PRISCILA CORRAINI

\title{
PERDA DE INSERÇÃO PERIODONTAL EM UMA POPULAÇÃO ISOLADA BRASILEIRA: PREVALÊNCIA, EXTENSÃO, SEVERIDADE E INDICADORES DE RISCO
}

São Paulo 


\section{Priscila Corraini}

Perda de inserção periodontal em uma população isolada brasileira: prevalência, extensão, severidade e indicadores de risco

Dissertação apresentada à Faculdade de Odontologia da Universidade de São Paulo para obtenção do título de Mestre pelo Programa de Pós-graduação em Ciências Odontológicas.

Área de concentração: Periodontia

Orientador: Prof. Titular Francisco Emílio Pustiglioni 
Catalogação-na-Publicação

Serviço de Documentação Odontológica

Faculdade de Odontologia da Universidade de São Paulo

Corraini, Priscila

Perda de inserção periodontal em uma população isolada brasileira: prevalência, extensão, severidade e indicadores de risco / Priscila Corraini; orientador Francisco Emílio Pustiglioni. - São Paulo, 2007.

$79 p$ : tabs., figs.; $30 \mathrm{~cm}$.

Tese (Mestrado - Programa de Pós-Graduação em Ciências Odontológicas. Área de Concentração: Periodontia) -- Faculdade de Odontologia da Universidade de São Paulo.

$\begin{array}{lll}\text { 1. Epidemiologia } & \text { 2. Fatores de risco } & \text { 3. Perda de inserção periodontal }\end{array}$ 4. Populações isoladas

CDD 617.632

BLACK D64

AUTORIZO A REPRODUÇÃO E DIVULGAÇÃO TOTAL OU PARCIAL DESTE TRABALHO, POR QUALQUER MEIO CONVENCIONAL OU ELETRÔNICO, PARA FINS DE ESTUDO E PESQUISA, DESDE QUE CITADA A FONTE E COMUNICADO AO AUTOR A REFERÊNCIA DA CITAÇÃO.

São Paulo, 1

Assinatura:

E-mail: pcorraini@usp.br 


\section{FOLHA DE APROVAÇÃO}

Corraini P. Perda de inserção periodontal em uma população isolada brasileira: prevalência, extensão, severidade e indicadores de risco [Dissertação de Mestrado]. São Paulo: Faculdade de Odontologia da Universidade de São Paulo; 2007.

São Paulo, / /

Banca Examinadora

1) Prof.(a) Dr.(a)

Titulação:

Julgamento:

Assinatura:

2) Prof.(a) Dr.(a)

Titulação:

Julgamento:

Assinatura:

3) Prof.(a) Dr.(a)

Titulação:

Julgamento:

Assinatura:

4) Prof.(a) Dr.(a)

Titulação:

Julgamento:

Assinatura:

5) Prof.(a) Dr.(a)

Titulação:

Julgamento:

Assinatura: 


\section{DEDICATÓRIA}

Dedico este trabalho à toda a população de Cajaíba que apoiou este projeto com convicção, contribuindo com um objetivo final: melhorar as condições de saúde geral e bucal por meio deste documento, em uma área tão esquecida pelas entidades governamentais neste Brasil. Agradeço especialmente ao Sr. Ceceu e Dona Yonne, a Dona Dica e Iolanda, ao Japão, a Rejane, Ananias e João Lucas, a Aninha, ao Valdinei, e a todos aqueles que fizeram deste trabalho algo real, fornecendo muitas vezes um lugar para dormir, um copo de café, um almoço, uma carona de barco, e me dando confiança para a execução deste projeto.

À Deus, por colocar no meu caminho este projeto tão ardiloso e cheio de obstáculos, mas tão recompensador. Com certeza aprendi muito com ele e sou outra pessoa após essa longa e difícil jornada.

Aos meus pais Orlando e Izildinha, que sempre me guiaram quanto aos corretos princípios, me inspiraram pelas pessoas excepcionais que são, e que além de tudo, sempre estiveram presentes com amor e confiança. Devo tudo o que sou hoje a vocês, que sempre me apoiaram e me mostraram a importância dos estudos na vida.

À minha avó Helena, por estar sempre viva em meu coração, me lembrando de sua eterna bondade e perseverança em ajudar os outros, me ensinando, nos poucos anos em que vivemos juntas, a entender que muitas vezes a sabedoria está em perdoar e amar ao outro, aceitando todas as diferenças entre nós. 


\section{AGRADECIMENTOS}

Ao meu orientador, Prof. Francisco Emílio Pustiglioni. Por confiar desde o início que este projeto poderia ser realizado, me apoiando, mesmo nos momentos difíceis, e me guiando em todos esses 3 anos e meio de pós-graduação. Pensar é o trabalho mais pesado que há, e seguramente é o bem mais valioso que levamos deste curso.

À Vibeke Bælum, por ter contribuído de maneira intensa com este trabalho, sempre disponível para ensinar e tirar dúvidas com seu brilhantismo. Com certeza aprendi muito sobre epidemiologia em minha estadia na Dinamarca, que não seria tão proveitosa e cheia de memórias agradáveis se não fosse por você.

Ao Sandro, por estar presente todos estes anos comigo em Cajaíba no veleiro e em campo, fazendo chuva ou sol, me ensinando a trabalhar em situações de campo. À Thais e a Laurinha, por estarem sempre presentes apoiando e participando disso.

Ao Prof. Cláudio Mendes Pannuti, pela amizade, e por sempre me incentivar, presente durante a fase de campo e durante a elaboração de todo o trabalho.

À Rosana Tramontina, pela amizade, constante incentivo, e que, com sua maneira perseverante e criativa de trabalhar, me guiou e me inspirou no caminho da periodontia desde os primeiros passos.

Ao Prof. Giuseppe Alexandre Romito, por sempre surgir com novas idéias e argumentações. 
Aos professores da disciplina de periodontia Roberto Lotufo, Giorgio de Micheli, Luiz Lima, José Hidelbrando Todescan, Marco Georgetti, Koto, Marina Conde e Silvia Rosana Carneiro (in memorian), que me ensinaram muito e enriqueceram meus conhecimentos em periodontia.

Ao Prof. Rui Vicente Oppermann e ao Prof. José Roberto Cortelli, por estarem sempre disponíveis, colaborando com a elaboração da metodologia deste trabalho.

À Regina Tamaki que, desde a iniciação científica no Departamento de Prótese Total da USP, me incentivou a participar de pesquisas e de me formar como especialista em Prótese, mesmo estando tão envolvida com esse trabalho.

À Profa. Araci, da Faculdade de Saúde Pública da USP, por colaborar durante a fase metodológica deste projeto.

Aos meus colegas de pós-graduação Hsu, Ivan, Verô, Giovane, Valéria, Adriane, Takiy, Fábio (querido sócio!) e Carla. Obrigado pela amizade, pelos Pirajás, pelas risadas, pelo conhecimento que construímos juntos, e digo JUNTOS MESMO, no famoso mocó. Em um lugar especial está a Cassita, eterna companheira de estudos, amiga querida que ganhei durante este curso, presente em todos os momentos da minha vida, na Alemanha, em Campinas, ou em qualquer lugar.....

À José Eduardo Rittes e Eduardo Viegas pelo apoio durante toda a fase de campo, sempre prestativos em ajudar, acreditando no trabalho.

À FAPESP, pelo auxílio à pesquisa (protocolo nº 04/15287-4).

À CAPES, pela bolsa de mestrado. 
"Planke seu jardim e decore sua alma, ao invés de esperar que alguém the traga flares. E você aprende que realmente pode suportar, que realmente é forke, e que pode ir muito mais longe depois de pensar que não se pode mais. E que a vida Kem valor e que você tem valor dianke da vida!"

William Shakespeare 
Corraini P. Perda de inserção periodontal em uma população isolada brasileira: prevalência, extensão, severidade e indicadores de risco [Dissertação de Mestrado]. São Paulo: Faculdade de Odontologia da USP; 2007.

\section{RESUMO}

Os objetivos deste estudo são avaliar a prevalência, extensão e severidade de perda clínica de inserção ( $\mathrm{NCl})$; e investigar as possíveis associações entre variáveis demográficas, socioeconômicas e comportamentais com $\mathrm{NCl}$ em uma população isolada brasileira. MATERIAL E MÉTODO: Todos os indivíduos com mais de 12 anos de idade foram identificados por um censo. Eles foram entrevistados por meio de um questionário estruturado e submetidos a um exame clínico completo que consistiu na avaliação de 6 sítios por dente em toda a boca. RESULTADOS: Dentre os 214 indivíduos que foram entrevistados e receberam exame clínico completo, $\mathrm{NCI} \geq 5 \mathrm{~mm}$ foi observado em $8 \%$, $37 \%, 70 \%, 83 \%$ e $100 \%$ dos indivíduos dentados nas faixas etárias de 12-19, 20-29, 30$39,40-49$ e 50 ou mais anos de idade; enquanto que a prevalência de $\mathrm{NCl} \geq 7 \mathrm{~mm}$ foi de $5 \%, 8 \%, 20 \%, 67 \%$ e $83 \%$ nas faixas anteriormente descritas, respectivamente. Análises de regressão logística multivariável identificaram quantidade de placa visível $(\mathrm{OR}=2,8)$, quantidade de cálculo supra-gengival $(20-50 \%$, OR = 2,9; e $>50 \%$, OR= 10,6), idade (OR $=11,4)$ e tabagismo $(\mathrm{OR}=2,4)$ como indicadores de risco para $\mathrm{NCl} \geq 5 \mathrm{~mm}$; e tabagismo $(\mathrm{OR}=8,2)$ para $\mathrm{NCl} \geq 7 \mathrm{~mm}$. CONCLUSÃO: Os resultados demonstraram que perda clínica de inserção é altamente prevalente nesta população isolada. A alta prevalência de $\mathrm{NCl}$ em faixas etárias jovens e a identificação de indicadores de risco tradicionais para $\mathrm{NCl}$ nesta população sugerem que fatores microbiológicos ou a susceptibilidade para a 
exposição de fatores ambientais possam ser considerados fatores-chave para a alta ocorrência encontrada nesta população.

Palavras-chave: Epidemiologia; Fatores de risco; Perda de inserção periodontal; Populações isoladas. 
Corraini P. Periodontal attachment loss in an untreated isolated population of Brazil: prevalence, extent, severity and risk indicators [Dissertação de Mestrado]. São Paulo: Faculdade de Odontologia da USP; 2007.

\section{ABSTRACT}

The aim of this study was to assess the prevalence, extent and severity of clinical attachment loss (CAL); and to investigate the associations between demographic, socioeconomic and behavioral risk indicators with CAL in an untreated isolated population in Brazil. METHODS: All subjects aged 12 years forward were selected by a census. They were submitted to a full-mouth clinical examination of six sites per tooth and were interviewed using a structured written questionnaire. RESULTS: Among the 214 subjects who were interviewed and clinical examined, $\mathrm{CAL} \geq 5 \mathrm{~mm}$ was observed in $8 \%, 37 \%, 70 \%$, $83 \%$, and $100 \%$ of the dentate subjects, depending on age; while the age dependent prevalence of CAL $\geq 7 \mathrm{~mm}$ was $5 \%, 8 \% 20 \%, 67 \%$ and $83 \%$, respectively. Multivariate analysis identified amount of plaque $(\mathrm{OR}=2.8)$, thresholds of supragingival calculus $(O R=2.9-10.6)$, age $(O R=11.4)$ and smoking $(O R=2.4)$ as risk indicators for $C A L \geq 5 \mathrm{~mm}$, and smoking $(\mathrm{OR}=8.2)$ for $\mathrm{CAL} \geq 7 \mathrm{~mm}$. CONCLUSION: The results demonstrate that CAL is highly prevalent in this isolated population. The high prevalence of CAL in young age groups and the observation of traditional risk indicators for CAL in this population suggest microbiological factors or host susceptibility to be key factors explaining the high levels of CAL found in this population.

Key words: Epidemiology; Risk factors; Periodontal Attachment Loss; Isolated Populations. 


\section{LISTA DE FIGURAS}

Figura 4.1 - Localização geográfica da reserva ecológica da Juatinga e da microárea Cajaíba

Figura 4.2 - Tipo de habitação freqüente na população de estudo 29

Figura 5.1 - População alvo e número final de indivíduos que receberam exame periodontal completo

Figura 5.2 - Número de dentes presentes por indivíduo do gênero masculino, de acordo com a idade 44

Figura 5.3 - Número de dentes presentes por indivíduo do gênero feminino, de acordo com a idade 44

Figura 5.4 - Distribuição de dentes perdidos e não-erupcionados por tipo de elemento dental e faixa etária .45

Figura 5.5 - Freqüência cumulativa de número de sítios por indivíduo com $\mathrm{NCl} \geq 1 \mathrm{~mm}$, de acordo com a idade 46

Figura 5.6 - Freqüência cumulativa de número de sítios por indivíduo com $\mathrm{NCl} \geq 3 \mathrm{~mm}$, de acordo com a idade.

Figura 5.7 - Freqüência cumulativa de número de sítios por indivíduo com $\mathrm{NCl} \geq 5 \mathrm{~mm}$, de acordo com a idade

Figura 5.8 - Freqüência cumulativa de número de sítios por indivíduo com $\mathrm{NCl} \geq 7 \mathrm{~mm}$, de acordo com a idade 48

Figura 5.9 - Porcentagem de dentes afetados por $\mathrm{NCl}$ em suas diferentes severidades por tipo de dente na maxila e mandíbula nos 
indivíduos adultos

50

Figura 5.10 - Porcentagem de dentes afetados por $\mathrm{NCl}$ em suas diferentes severidades por tipo de dente na maxila e mandíbula nos indivíduos adultos-jovens (20-29 anos) 50

Figura 5.11 - Porcentagem de dentes afetados por NCl em suas diferentes severidades por tipo de dente na maxila e mandíbula nos indivíduos de 12 a 19 anos

Figura 5.12 - Distribuição da freqüência cumulativa de indivíduos de acordo com a proporção de sítios com placa visível e cálculo supra-gengival 


\section{LISTA DE TABELAS}

Tabela 4.1 - Dados demográficos da população alvo em 2003

Tabela 4.2 - Dados demográficos da população alvo, segundo o censo realizado em 2006

Tabela 4.3 - Valores de glicose plasmática $(\mathrm{mg} / \mathrm{dL})$ para diagnóstico de

Diabetes Mellitus e seus estágios pré-clínicos 35

Tabela 5.1 - Distribuição da população de estudo de acordo com idade e gênero .. 42

Tabela 5.2 - Frequência de edentulismo e número médio de dentes presentes, cariados ou obturados, em indivíduos dentados por idade e gênero 43

Tabela 5.3 - Prevalência (\%) e extensão de $\mathrm{NCl} \geq 3 \mathrm{~mm}, \mathrm{NCl} \geq 5 \mathrm{~mm}$ e $\mathrm{NCl} \geq 7 \mathrm{~mm}$ de acordo com a idade e gênero.

[ ] denota o IC de $95 \%$ para a extensão 49

Tabela 5.4 - Distribuição dos preditores candidatos demográficos, ambientais e biológicos com relação à prevalência e extensão de $\mathrm{NCl} \geq 5 \mathrm{~mm}$ e $\geq 7 \mathrm{~mm}$ 53

Tabela 5.5 - Análise de regressão logística univariável entre as variáveis dependentes prevalência de $\mathrm{NCl} \geq 5 \mathrm{~mm}$ e $\mathrm{NCl} \geq 7 \mathrm{~mm}$ e os preditores candidatos ou variáveis independentes demográficas, ambientais e biológicas

Tabela 5.6 - Modelo final de regressão logística multivariável para as variáveis dependentes prevalência de $\mathrm{NCl} \geq 5 \mathrm{~mm}$ e $\mathrm{NCl} \geq 7 \mathrm{~mm}$ .56 


\section{LISTA DE ABREVIATURAS E SIGLAS}

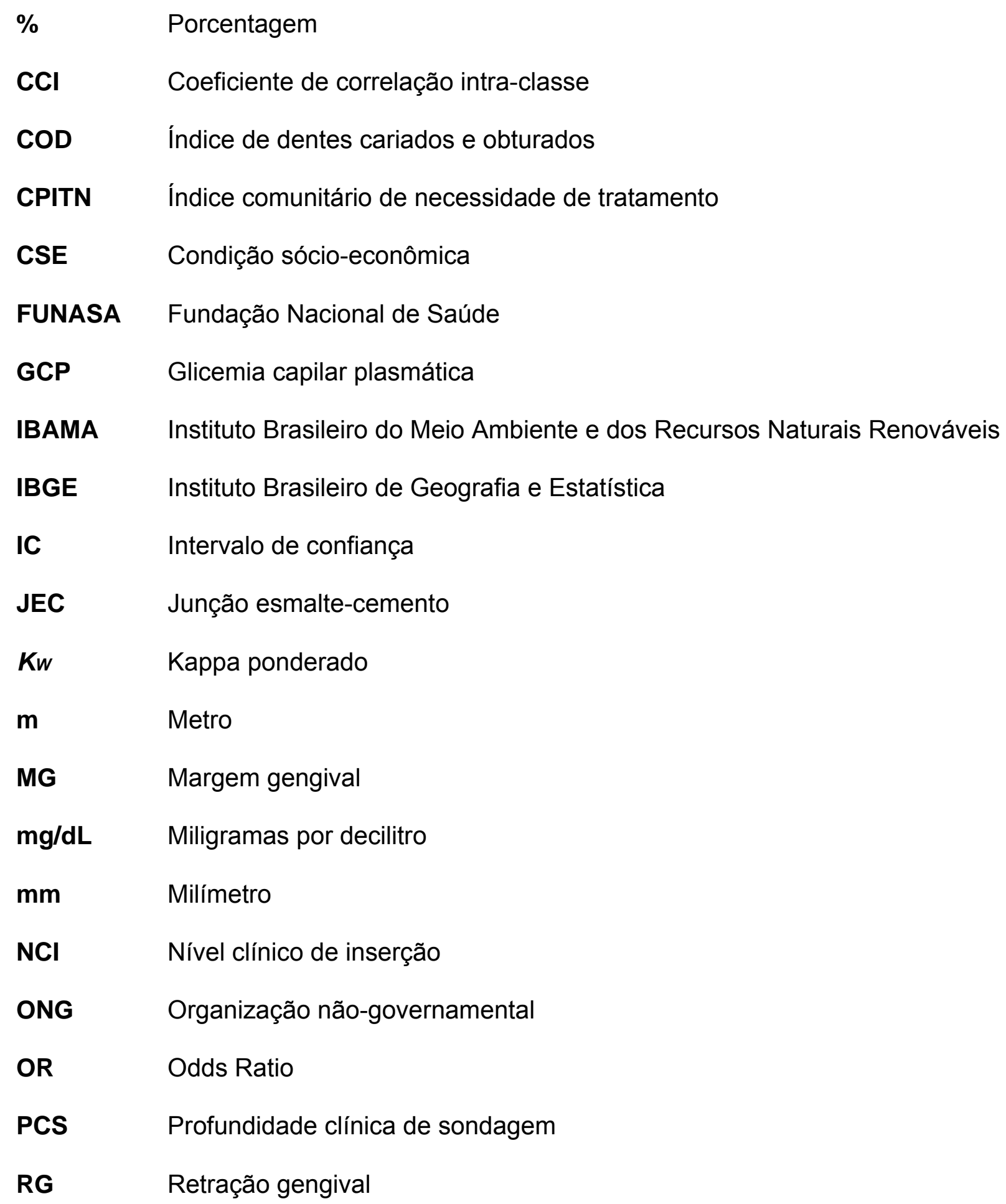




\section{SUMÁRIO}

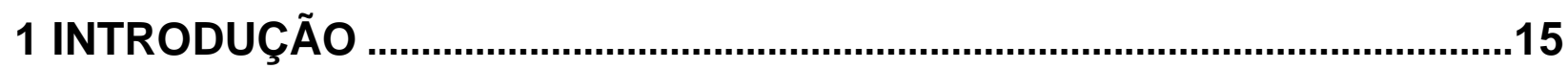

2 REVISÃO DA LITERATURA ........................................................................18

2.1 Epidemiologia das doenças periodontais em populações isoladas brasileiras.. 19

2.2 Definição de casos na Epidemiologia das doenças periodontais ........................ 21

2.3 Protocolos parciais de exame clínico periodontal ................................................ 21

2.4 Fatores e Indicadores de risco para as doenças periodontais ............................. 23

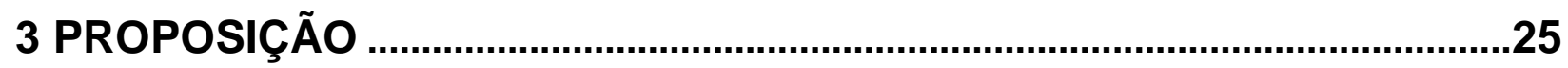

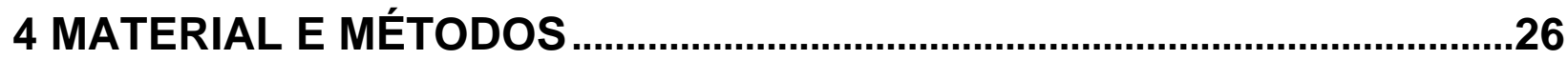

4.1 Delineamento do estudo e casuística ........................................................... 26

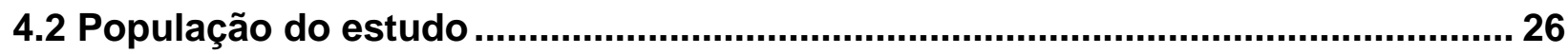

4.3 Tamanho da população e procedimentos de amostragem ................................... 29

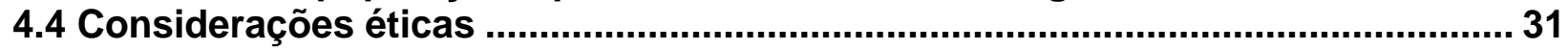

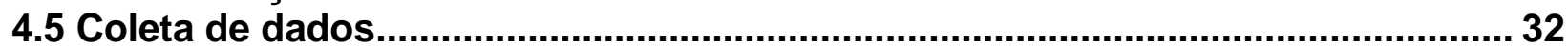

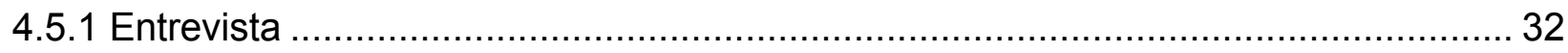

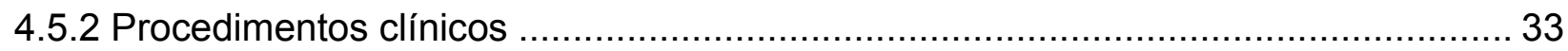

4.6 Avaliação da reprodutibilidade das variáveis................................................... 36

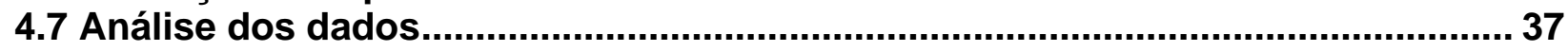

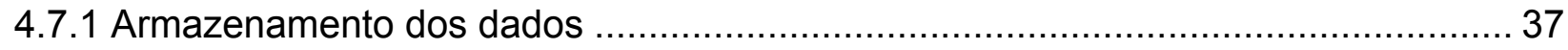

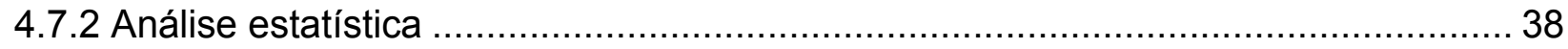

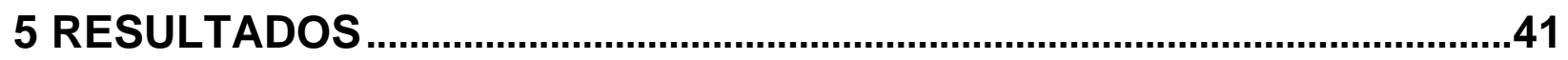

6 DISCUSSÃO

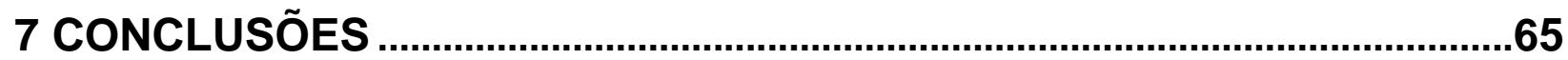

REFERÊNCIAS .................................................................................. 66

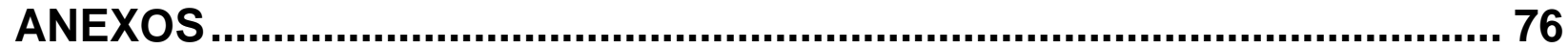

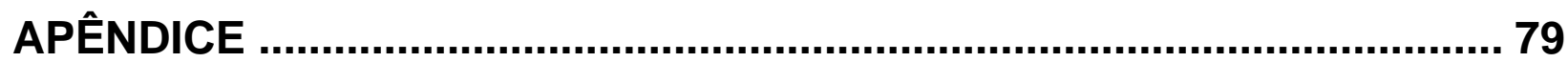




\section{INTRODUÇÃO}

Dentre os problemas de saúde bucal que atingem grande parcela da população mundial, estão a doença cárie e as doenças periodontais (ALBANDAR; BRUNELLE; KINGMAN, 1999; BROWN; BRUNELLE; KINGMAN, 1996; CHAVES, 1986; MARQUES, 2000; PETERSEN et al., 2005).

A prevalência de doença periodontal destrutiva, especialmente em suas formas mais severas, varia significantemente em diferentes regiões do mundo (ALBANDAR; RAMS, 2002; ALBANDAR, 2002). Há indícios de que ela é mais prevalente em países em desenvolvimento (SUSIN, 2004) e grupos carentes de populações e etnias específicas (ALBANDAR; RAMS, 2002), quando comparada a países desenvolvidos (ALBANDAR; BRUNELLE; KINGMAN, 1999).

Apesar de um grande número de estudos realizados (BORREL; PAPAPANOU, 2005), a epidemiologia das doenças periodontais destrutivas permanece pouco compreendida. Isto ocorre, entre outros fatores, devido à existência de diferentes desfechos clínicos para definir uma única doença (BAELUM, 1998; BORREL; PAPAPANOU, 2005; OPPERMANN et al., 2005), levando à divergências de opinião quanto à definição da mesma (BAELUM; LOPEZ, 2003; GJERMO et al., 2002; OPPERMANN et al., 2005; VAN DER VELDEN, 2005). Além disso, mudanças recentes referentes ao paradigma das doenças periodontais (BAELUM, 1998) permitiram gradualmente a investigação de fatores de risco além dos etiológicos locais microbianos (BAELUM; LOPEZ, 2004). 
Exemplos significativos de fatores de risco para as doenças periodontais destrutivas são o tabagismo (ALBANDAR, 2002; HEITZ-MAYFIELD, 2005; TOMAR; ASMA, 2000) e o diabetes não compensado (EMRICH; SHOLSSMAN; GENCO, 1991; SOLSKOLNE, 1998). A importância do tabagismo foi potencializada por estudos que o sugerem como causa de uma "epidemia silenciosa" de periodontite (HUJOEL et al., 2003), sendo responsável por aproximadamente metade de todos os casos de periodontite (SUSIN et al., 2004a; TOMAR; ASMA, 2000). Já com relação à associação entre o diabetes e as doenças periodontais destrutivas, a evidência mais marcante provem dos estudos realizados na população dos índios Pima que apresentavam uma prevalência extremamente alta de diabetes mellitus tipo 2 (SOLSKOLNE, 1998). Estudos contrastando índios Pima diabéticos e não-diabéticos demonstraram uma prevalência e severidade significativamente mais alta de doenças periodontais destrutivas no grupo diabético (EMRICH; SHOLSSMAN; GENCO, 1991).

Um melhor entendimento dos fatores de risco para as doenças periodontais é proporcionado por estudos de "extremos". Esta abordagem foi realizada em estudos contrastando estudantes noruegueses e trabalhadores de uma plantação de chá em Sri Lanka (LÖE et al., 1978), e na comparação entre padrões de doenças periodontais destrutivas entre diferentes populações em países desenvolvidos e em desenvolvimento (BAELUM et al., 1996). Porém, apenas idade, gênero e condições de higiene foram incluídos na avaliação de risco nestes estudos, fatores estes insuficientes para explicar os grandes contrastes encontrados nas populações avaliadas.

Seguindo esta linha de raciocínio, informações que podem ser obtidas por estudos representando, da melhor maneira possível, a história natural das doenças periodontais, tornam-se indispensáveis. Nas populações isoladas, geralmente encontradas em países 
em desenvolvimento, um controle de fatores de confusão é obtido naturalmente pela restrição da influência da utilização de medicamentos, à influências do tratamento odontológico, principalmente quanto à restrição ao tratamento periodontal, extrações dentárias e procedimentos de higiene bucal (VAN DER VELDEN et al., 2006). Assim sendo, o estudos destas populações, sob o aspecto epidemiológico, pode fornecer informações importantes à respeito das doenças periodontais destrutivas. 


\section{REVISÃO DA LITERATURA}

A Epidemiologia é o estudo do processo saúde-doença em populações humanas (AAP, 2005; ROUQUARYOL; ALMEIDA FILHO, 1994). Ela analisa a distribuição e os fatores determinantes de condições relacionadas a este processo, ou eventos, em populações específicas (LAST, 2001). Ela também pode sugerir medidas específicas de prevenção, controle e erradicação de doenças, fornecendo indicadores que sirvam de suporte ao planejamento, administração e avaliação de ações de saúde (ROUQUARYOL; ALMEIDA FILHO, 1994).

Por meio dos levantamentos epidemiológicos é possível estimar a condição de saúde bucal de diferentes grupos populacionais. Este conhecimento é indispensável para a proposição de ações adequadas a cada uma de suas necessidades e riscos. Informações fornecidas por esses levantamentos possibilitam comparações no tempo, no espaço e avaliações do impacto diferencial de fatores de risco e proteção, bem como dos programas de saúde relativos aos agravos e condições considerados (FRIAS; ANTUNES; NARVAI, 2004).

Além de constituir-se em um importante instrumento da saúde coletiva para a prevenção de doenças, a epidemiologia também possui um importante aspecto científico (BAELUM, 1998), encarregando-se de analisar doenças ou condições em relação aos indivíduos, ambientes e períodos de tempo. Com base nesse entendimento, é que se consegue uma compreensão das disparidades nos padrões de saúde/doença encontrados (KINGMAN; ALBANDAR, 2002). Esclarece a sua magnitude, natureza, entre quais grupos 
de indivíduos ou populações ocorre e em quais lugares se manifesta (RÖSING; OPPERMANN, 2001).

\subsection{Epidemiologia das doenças periodontais em populações isoladas brasileiras}

$\mathrm{Na}$ literatura periodontal mundial, um importante marco foi definido a partir de um estudo epidemiológico longitudinal realizado em uma população isolada, em Sri Lanka, de 1970 a 1985. Esta população não possuía acesso a nenhum tipo de tratamento periodontal, bem como a hábitos de higiene oral (LÖE et al., 1986). Propondo-se a avaliar a história natural da doença periodontal em humanos, Löe et al. (1986) acompanharam os níveis clínicos de inserção em 161 indivíduos do sexo masculino de 14 a 46 anos de idade por um período de 15 anos. Todos os indivíduos pesquisados apresentaram alterações periodontais inflamatórias na maioria dos sítios. No entanto, alguns desenvolveram periodontite e outros não. A progressão da doença periodontal tendeu a ocorrer com o tempo, porém variou significativamente entre os indivíduos. Os autores ressaltaram que a homogeneidade do grupo quanto à etnia, o ambiente, a condição sócio-econômica (CSE) e a nutrição, sugerem que importância especial seja dada às grandes diferenças dentre estas características, e como estas poderiam estar influenciando a progressão das doenças periodontais.

No Brasil, não é possível traçar o perfil epidemiológico periodontal de modo satisfatório, que leve em consideração a heterogeneidade que certamente existe no âmbito dos povos isolados, a maioria deles indígenas (ARANTES, 2003). Nem os indicadores sociodemográficos básicos, como taxa de mortalidade infantil, esperança de 
vida ao nascer ou principais causas de morbimortalidade estão disponíveis (COIMBRA JR; SANTOS, 2000), com exceção de poucas populações.

Como esperado, dos poucos estudos transversais existentes em comunidades indígenas, na maioria dos casos, os níveis de biofilme e sangramento à sondagem apresentaram-se altos (ARANTES, 2003; DONNELLY et al., 1977; FRATUCCI, 2000; NISWANDER, 1967; RONDEROS; PIHLSTROM; HODGES, 2001). O mesmo ocorreu com relação à presença de cálculo, verificado entre 53,73 a 96\% dos indivíduos examinados nestes estudos (FRATUCCI, 2000; GALATI, 2003; RONDEROS; PIHLSTROM; HODGES, 2001), já que a maioria não possui hábitos de higiene bucal (ARANTES; SANTOS; COIMBRA JR, 2001; DONNELLY et al., 1977; FRATUCCI, 2000; NISWANDER, 1967; TUMANG; PIEDADE, 1968), mesmo após a assistência prestada pela Fundação Nacional de Saúde (FUNASA), do Ministério de Saúde do Brasil, em uma das localidades indígenas estudadas (GALATI, 2003). Com relação ao único estudo que permitiu o cálculo da prevalência de doença periodontal severa, em indivíduos com mais de 20 anos (RONDEROS; PIHLSTROM; HODGES, 2001), foi encontrado um valor médio de $7,1 \%$ da população indígena afetada, mais baixo do que a média encontrada nas Américas Central e do Sul (GJERMO et al., 2002).

Apenas dois trabalhos transversais descrevendo condições periodontais de populações isoladas não-indígenas foram realizados no Brasil. Galati (2003), estudando duas comunidades caiçaras no litoral sul do estado de São Paulo, não encontrou indivíduos (idade entre 5-12 anos) com escores de CPI entre 3 e 4 no Vale do Ribeira, e encontrou um percentual de $8,35 \%$ de indivíduos com escores entre 3 e 4 na Vila Itinguçu. Porém, limitações metodológicas quanto à amostragem, distribuição das variáveis demográficas (apenas $12,82 \%$ da amostra possuía idade maior ou igual a 12 anos, dentre 
outros aspectos) e índice periodontal empregado, dificultam a validade e confiabilidade destes resultados. Segundo, Ferreira e Da Costa (2004), estudando uma comunidade isolada de raça/etnia negra de Minas Gerais, por meio de exame periodontal completo de perda de inserção em toda a população alvo (104 indivíduos), encontraram 9,6\% dos indivíduos com doença periodontal na sua forma severa, prevalência esta similar à detectada em outras localidades do Brasil e do Mundo.

\subsection{Definição de casos na epidemiologia das doenças periodontais}

Borrel e Papapanou (2005), confirmando as acertivas de Papapanou (1996), relataram que o pré-requisito fundamental para qualquer estudo epidemiológico que avalie doenças periodontais é a determinação de um critério preciso para definir a doença sob investigação. No entanto, na literatura periodontal, nenhum critério uniforme ainda foi estabelecido (AAP, 2005; ALBANDAR; BRUNELLE; KINGMAN, 1999; BAELUM; LOPEZ, 2003; BECK et al., 1999; BORRELL; PAPAPANOU, 2005; DYE; SELWITZ, 2005; GJERMO et al., 2002; GREENE, 1986; KINGMAN; ALBANDAR, 2002; PAPAPANOU, 1996; OPPERMANN et al., 2005; PERSSON, 2005; VAN DER VELDEN, 2000).

Atualmente, a mensuração do nível clínico de inserção é geralmente aceita como o mais adequado indicador para a identificação de casos de periodontite (BECK, 1994; GOODSON, 1992; ESTADOS UNIDOS, 2004), tanto em ensaios clínicos, quanto em levantamentos epidemiológicos. No entanto, esta medida ainda é pouco utilizada em 
estudos epidemiológicos de doença periodontal, principalmente na América Latina (GJERMO et al., 2002).

\subsection{Protocolos parciais de exame clínico periodontal}

Beck e Löe (1993), afirmaram que o exame periodontal em toda a boca, isto é, exame periodontal de 6 sítios por dente em todos os dentes presentes na maxila e na mandíbula, é comumente considerado o exame padrão-ouro ("gold-standard”) na avaliação das doenças periodontais. No entanto, este método consome muito tempo e exige recursos elevados, além de impor um fardo significativo para o sujeito da pesquisa e para o examinador, podendo levar a maiores erros de sondagem e a uma maior taxa de desistência em levantamentos epidemiológicos (SUSIN; KINGMAN; ALBANDAR, 2005).

Em estudos epidemiológicos avaliando as doenças periodontais, diversos protocolos parciais de exame têm sido propostos e utilizados (BORREL; PAPAPANOU, 2005; KINGMAN; ALBANDAR, 2002). No entanto, a habilidade destes protocolos em refletir as condições periodontais presentes em toda a boca têm sido questionadas por subestimar a prevalência de doenças periodontais, ou, tanto sub (BORGES-YÁÑEZ; MAUPOMÉ; JIMÉNEZ-GARCÍA, 2004; BORREL; PAPANOU, 2005; HUNT; FANN, 1991; KINGMAN et al., 1988; KINGMAN; ALBANDAR, 2002), como superestimar a prevalência, extensão e severidade de doenças periodontais em uma dada população (DIAMANTIKIPIOTI et al., 1993; KINGMAN; ALBANDAR, 2002; PAPAPANOU, 1996; PERSSON, 
2005), além de ainda não existir nenhum consenso sobre quais sítios devem ser avaliados para uma melhor representatividade.

Albandar, Brunelle e Kingman (1999), por meio de um estudo epidemiológico em adultos, com idade acima de 30 anos, concluiram que, se a destruição periodontal parece ser específica em alguns sítios e dentes em especial, é improvável que o exame de alguns dentes pré-determinados pelo pesquisador ou número limitado de sítios proverá uma representação fiel do nível e padrão das doenças periodontais.

No Brasil, Susin, Kingman e Albandar (2005), por meio de um estudo avaliando o efeito de protocolos parciais de exame clínico periodontal na estimativa de prevalência de perda clínica de inserção periodontal em uma população urbana, concluiram, após comparação de um protocolo periodontal completo, realizado em 6 sítios por dente em toda a boca, com mais 7 protocolos parciais de exame clínico periodontal, que protocolos parciais de exame subestimam consistentemente a prevalência de nível clínico de inserção e que a extensão desta subestimação é dependente do tipo de protocolo parcial empregado e das características da população estudada. Além disso, os autores relataram que a utilização de sistemas de protocolos parciais podem explicar parte dos diferentes achados entre diferentes estudos.

\subsection{Fatores e indicadores de risco para as doenças periodontais}

A ocorrência de gengivite parece necessária para que ocorra o desenvolvimento da periodontite (ALBANDAR et al., 1998; AXELSSON; ALBANDAR; RAMS, 2002; BAELUM, 
1998; NEELY et al., 2001; SCHATZLE et al., 2003a). No entanto, nem todos os sítios com gengivite desenvolvem periodontite (AAP, 2005; ALBANDAR et al., 1996; LÖE et al., 1986; NEELY et al., 2001; SCHATZLE et al., 2003(a e $\underline{b})$ ). Além disso, há evidência de que, dentre os indivíduos com periodontite, somente uma limitada parcela destes indivíduos (5 a 20\%) (AAP, 2005), apresentará perda severa dos tecidos periodontais de suporte (ALBANDAR et al., 1998; ALBANDAR; BRUNELLE; KINGMAN, 1999; ALBANDAR; RAMS, 2002; BAELUM, 1998; OLIVER; BROWN; LÖE, 1998). Estes aspectos da individualidade na predisposição às doenças periodontais demonstram a importância em se identificar fatores de risco.

Por meio de uma ampla revisão da literatura, Borrell e Papapanou (2005), confirmando as constatações de Genco et al. (1996), mostraram a importância da identificação dos seguintes fatores de risco para doenças periodontais: diabetes, tabagismo e a presença, na cavidade oral, de certas espécies bacterianas. Indicadores de risco incluem: idade, gênero, raça/etnia, CSE (GROSSI et al., 1994; ALBANDAR, 2002), e a presença de polimorfismos genéticos em algumas espécies bacterianas (BORRELL; PAPAPANOU, 2005). Outros determinantes, tais como hereditariedade, diversas doenças sistêmicas incomuns, e estresse psico-social, também têm sido considerados importantes candidatos na avaliação dos riscos para estas doenças (AAP, 2005). 


\section{PROPOSIÇÃO}

Os objetivos deste trabalho são:

3.1 Avaliar a prevalência, extensão e severidade de perda clínica de inserção periodontal em uma população brasileira;

3.2 Investigar as associações entre as variáveis demográficas, comportamentais e biológicas com a perda de inserção periodontal nesta população. 


\section{MATERIAL E MÉTODOS}

\subsection{Delineamento do estudo e casuística}

Foi conduzido um estudo transversal analítico, com o objetivo de avaliar a população isolada presente na microárea Cajaíba, pertencente ao município de Paraty, estado brasileiro do Rio de Janeiro, localizado na região costeira sudeste do Brasil.

\subsection{População do estudo}

A população alvo compreendeu todos os indivíduos com mais de 12 anos de idade, que consentiu com os objetivos do estudo. A idade de 12 anos foi considerada, por representar a idade na qual, na maioria dos casos, a dentição permanente já está completamente erupcionada (WHO, 1997).

A microárea Cajaíba, pertencente ao município de Paraty-RJ, corresponde à região da reserva ecológica da Juatinga (Lei $n^{0} 1.859$, de 01/10/1991; Decreto $n^{\circ} 17.981$, de 30/10/1992). Esta população, segundo dados da Secretaria Municipal de Saúde de Paraty, em 2003 (dados não publicados) compreendeu mais de 642 habitantes, vivendo em seis praias: Pouso do Cajaíba, Ipanema, Calhaus, Galhetas, Itaoca e Praia Grande. 
A população de Cajaíba permanece efetivamente isolada do restante do continente pela existência dos seguintes limitantes geográficos: as Pontas da Cajaíba (Figura 4.1) e da Juatinga; e a reserva ecológica da Juatinga, onde existe também o pico do Cairuçu (1.100 $\mathrm{m}$ de altitude). Devido ao seu isolamento, é freqüente a presença de consangüinidade entre os indivíduos desta população.

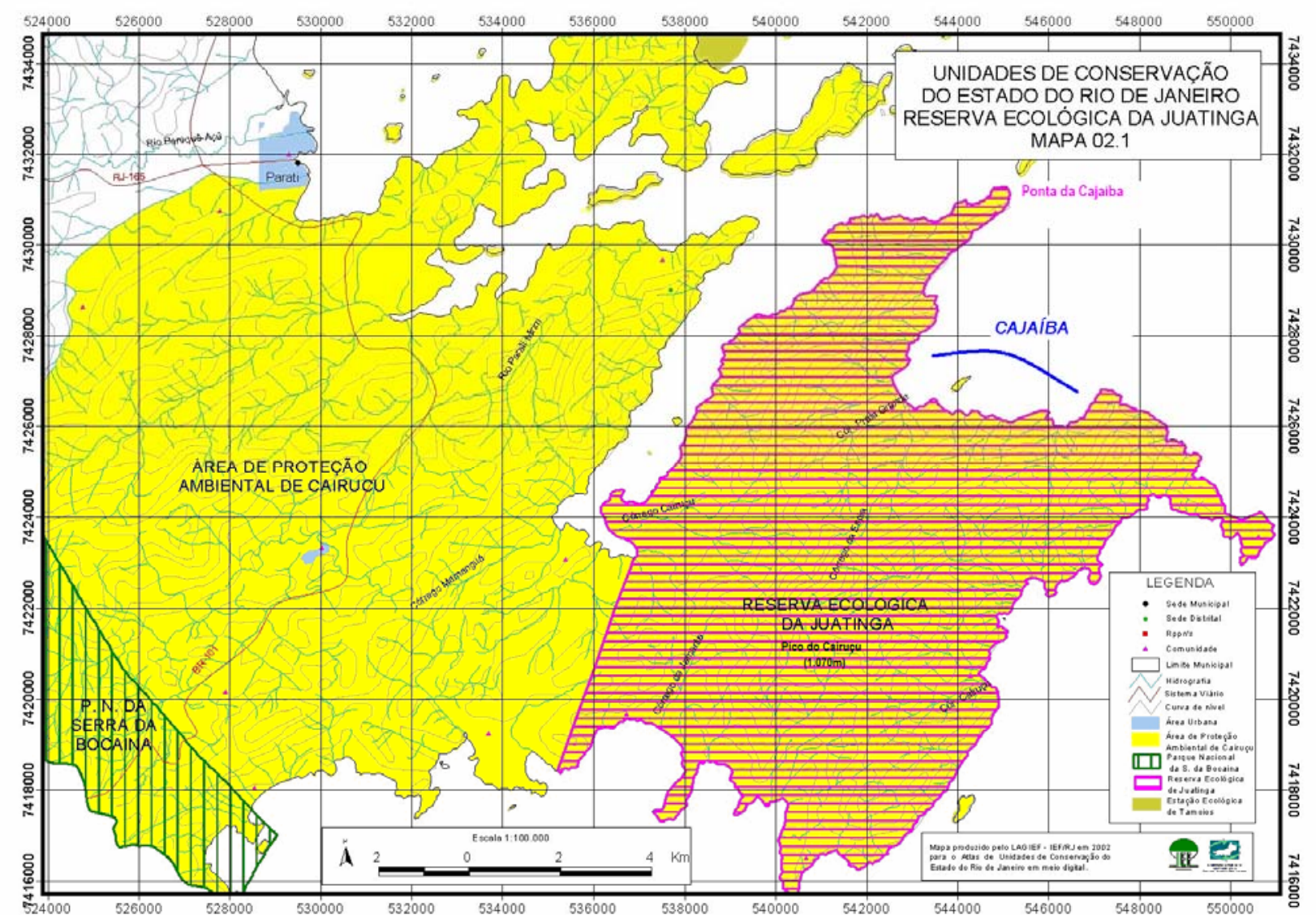

Figura 4.1 - Localização geográfica da reserva ecológica da Juatinga e da microárea Cajaíba

A Reserva Ecológica da Juatinga localiza-se no extremo sul do Estado do Rio de Janeiro, no Município de Paraty (Figura 4.1), e está inserida na Área de Proteção Ambiental de Cairuçu, administrada pelo IBAMA. Esta reserva foi criada com o objetivo de 
preservar o ecossistema local composto por remanescentes florestais de Mata Atlântica, restingas, manguezais e costões rochosos, além de tentar preservar a típica cultura caiçara. Com cerca de 8.000 hectares (80 quilômetros quadrados), ela abriga doze núcleos de ocupação de populações tradicionais que se distribuem em trechos ao longo do litoral e vivem de pesca artesanal e agricultura de subsistência. Os núcleos se relacionam entre si e utilizam a cidade de Paraty como centro de comércio e serviços, apesar da precariedade de acesso - a pé por picadas ou por barcos. (http://www.ief.ri.gov.br/unidades/rej.html, 2005).

Na região não existe abastecimento de água pela rede pública, sendo a mesma disponível por meio de poços ou nascentes. Também não existe sistema de esgoto, nem energia elétrica na região. A coleta pública de lixo ocorre somente em $19,18 \%$ das residências. Os tipos de habitação presentes são na maioria constituídas por tijolo/adobe (Figura 4.2). 


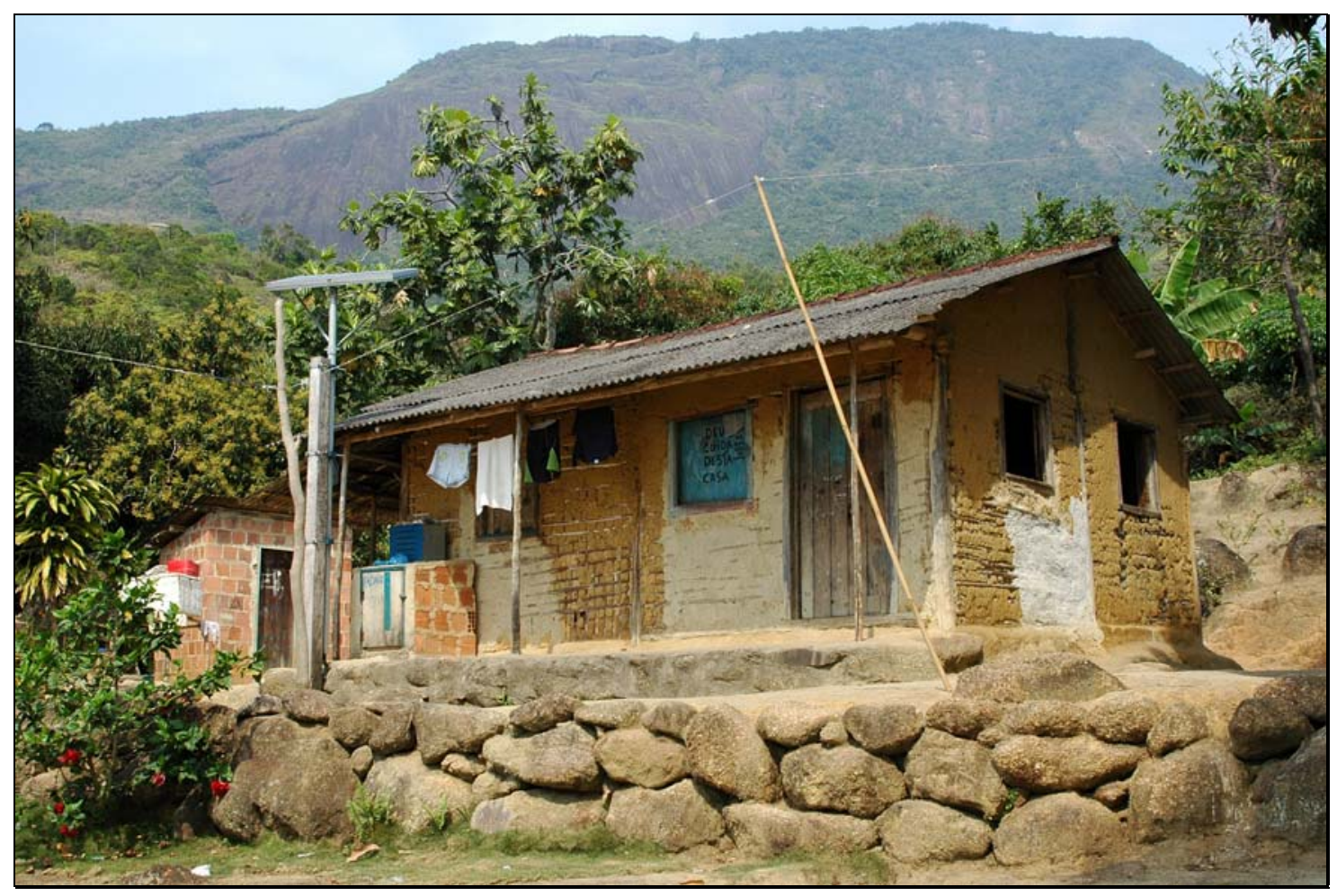

Figura 4.2 - Tipo de habitação freqüente na população de estudo

Com relação aos serviços de saúde nesta região, não existe nenhum posto de saúde na área, tanto médico quanto odontológico. O acesso aos serviços de saúde bucal é esporádico e limitado a exodontias na presença de sintomatologia dolorosa aguda, e a alguns mínimos procedimentos restauradores temporários em crianças.

\subsection{Tamanho da população e procedimentos de amostragem}

Segundo dados da Secretaria Municipal de Saúde de Paraty (dados não publicados), a população com mais de 10 anos de idade compreendeu, em 2003, um 
número de 458 habitantes, sendo 250 do gênero masculino e 208 do feminino. Desta maneira, a população alvo não podia ser definida com precisão, já que os dados obtidos com relação ao número de habitantes foram organizados pela seguinte categoria de faixas etárias: <1, 1-4, 5-6, 7-9, 10-14, 15-19, 20-39, 40-49, 50-59, >60 (Tabela 4.1).

Tabela 4.1 - Dados demográficos da população alvo em 2003

\begin{tabular}{|c|c|c|c|c|c|c|c|c|c|c|c|}
\hline \multicolumn{10}{|c|}{ CENSO 2003 } \\
\hline Género & \multicolumn{10}{c|}{ FAIXA ETÁRIA (anos) } \\
\cline { 2 - 13 } & $<1$ & $1-4$ & $5-6$ & $7-9$ & $10-14$ & $15-19$ & $20-39$ & $\mathbf{4 0 - 4 9}$ & $\mathbf{5 0 - 5 9}$ & $>\mathbf{6 0}$ & Total \\
\hline Masculino & 7 & 39 & 24 & 24 & 41 & 35 & 102 & 23 & 27 & 22 & 344 \\
\hline Feminino & 6 & 35 & 15 & 34 & 35 & 27 & 84 & 24 & 22 & 16 & 298 \\
\hline Total & 13 & 74 & 39 & 58 & 76 & 62 & 186 & 47 & 49 & 38 & 642 \\
\hline
\end{tabular}

Além dos dados relacionados ao número de habitantes por faixa etária e gênero, e ao censo de uma população, é necessário um conhecimento prévio da prevalência das doenças em estudo na população alvo, para que seja possível determinar, com precisão, o tamanho da amostra do universo a ser estudado (LEVY; LEMESHOW, 1999).

Uma vez que não existiam dados censitários federais (IBGE), nem municipais (Prefeitura de Paraty) relevantes a respeito dos elementos unitários da população alvo, nem dados referentes à prevalência de doença periodontal nesta população, foi realizado um censo (LEVY; LEMESHOW, 1999) em concomitância com a realização deste estudo.

O resultado deste censo, realizado em 2006 (Tabela 4.2), demonstrou que a população de Cajaíba decresceu drasticamente em um período de apenas 3 anos. Este declínio ocorreu por uma intensa emigração para a cidade de Paraty que ocorreu neste período, provocada por proprietários de duas das praias. No entanto, 358 indivíduos ainda 
permanecem na área, e destes, 264 indivíduos possuíam 12 ou mais anos de idade e, portanto, foram elegíveis para participação neste estudo.

Tabela 4.2 - Dados demográficos da população alvo, segundo o censo realizado em 2006

\begin{tabular}{|c|c|c|c|c|c|c|c|c|c|c|c|c|}
\hline \multicolumn{10}{|c|}{ CENSO 2006 } \\
\hline Gênero & \multicolumn{10}{c|}{ FAIXA ETÁRIA (anos) } \\
& $<\mathbf{1}$ & $\mathbf{1 - 4}$ & $\mathbf{5 - 6}$ & $\mathbf{7 - 9}$ & $\mathbf{1 0 - 1 4}$ & $\mathbf{1 5 - 1 9}$ & $\mathbf{2 0 - 3 9}$ & $\mathbf{4 0 - 4 9}$ & $\mathbf{5 0 - 5 9}$ & $\mathbf{8 0}$ & Total \\
\hline Masculino & $\mathbf{3}$ & 21 & $\mathbf{5}$ & 15 & 20 & 17 & 78 & 19 & 11 & 16 & 205 \\
\hline Feminino & 4 & 6 & 10 & 12 & 21 & 10 & 51 & 14 & 17 & 8 & 153 \\
\hline Total & 7 & 27 & 15 & 27 & 41 & 27 & 129 & 33 & 28 & 24 & 358 \\
\hline
\end{tabular}

\subsection{Considerações éticas}

O estudo foi autorizado, previamente à sua realização, pelos líderes de cada comunidade de Cajaíba e pelo prefeito de Parati, centro administrativo responsável pela área em que Cajaíba se encontra, após o detalhamento de seus objetivos e benefícios para a população. Além disso, o protocolo de pesquisa e o termo de consentimento livre e esclarecido foram submetidos e aprovados pelo Comitê de Ética da Faculdade de Odontologia da Universidade de São Paulo (Anexo A).

Devido à alta freqüência de analfabetismo na população alvo, o termo de consentimento livre e esclarecido (Anexo B) foi lido à todos os indivíduos elegíveis. A todos os indivíduos que aceitaram a participação no estudo foi solicitado a sua assinatura, 
apenas após o completo entendimento de seu conteúdo. No caso de menores de idade, foi solicitada a um responsável legal a assinatura.

Este estudo contou com a parceria da ONG Sorriso Marinho. Os participantes deste estudo receberam tratamento urgencial, quando necessário, por meio de extrações ou restaurações temporárias pelos dentistas ligados a esta ONG.

\subsection{Coleta de dados}

A coleta de dados em campo foi conduzida entre outubro de 2005 e novembro de 2006.

\subsubsection{Entrevista}

Todos os indivíduos elegíveis da população que consentiram em participar desse estudo receberam visitas em suas residências e foram convidados a participar de uma entrevista realizada por um único entrevistador, baseado em um questionário estruturado. As seguintes informações foram coletadas durante as entrevistas: idade (em anos), gênero, número de indivíduos vivendo na mesma residência (aglomeração familiar), presença de renda monetária (sim/não) e, se aplicável, seu valor mensal aproximado, em reais. Os indivíduos também foram questionados quanto à possibilidade de ler e escrever 
(sim/não), anos de escolaridade, se recebeu tratamento odontológico durante a vida (sim/não). A freqüência de higiene bucal diária e hábitos de tabagismo também foram investigados. As questões relacionadas ao tabagismo incluíram situação atual ou passada de tabagismo (sim/não), duração do hábito para fumantes e ex-fumantes (em anos), tempo desde o término do hábito para ex-fumantes (em anos), tipo de hábito de tabagismo, bem como o número de itens fumados diariamente para fumantes e exfumantes. Alguns indivíduos desconheciam sua idade exata que, portanto, foi estimada.

\subsubsection{Procedimentos clínicos}

Os exames clínicos foram realizados por um único examinador treinado e calibrado. Um auxiliar odontológico era responsável pela anotação dos dados em uma ficha (Anexo C), para melhor organização dos resultados obtidos. Todos os exames clínicos foram realizados sob condições de campo, isto é, nas residências dos participantes. Foram realizados durante o dia com o auxílio de uma lanterna tipo mineirador ${ }^{1}$ fixada na cabeça do examinador, que serviu como fonte de iluminação (SEGUNDO; FERREIRA; COSTA, 2004). Para evitar cansaço excessivo do examinador, levando a variações na acuidade visual e no senso de tato (WHO, 1997), foram realizados no máximo 10 exames clínicos durante o dia. 
Utilizando um espelho clínico plano ${ }^{2}$, e uma sonda milimetrada manual ${ }^{3}$, os sulcos/bolsas foram examinados em 6 sítios por dente (faces mésio-lingual, lingual, distolingual, mésio-vestibular, vestibular e disto-vestibular) em todos os dentes permanentes, com exceção dos terceiros molares e os dentes em processo de erupção. Quantidades excessivas de cálculo que dificultassem um correto registro dos parâmetros pela sonda foram removidas antes da sondagem, com auxílio de curetas ${ }^{4}$. Os seguintes parâmetros clínicos foram registrados:

1. Profundidade clínica de sondagem (PCS): distância ( $\mathrm{mm}$ ) compreendida entre a margem gengival e o fundo do sulco gengival ou da bolsa periodontal.

2. Distância da linha esmalte-cemento à margem gengival (LEC-MG): distância $(\mathrm{mm})$ que vai da linha esmalte-cemento à margem gengival. Se a LEC estivesse localizada apicalmente à margem gengival, o parâmetro receberia um valor negativo.

3. Nível clínico de inserção ( $\mathrm{NCl})$ : é o valor correspondente à soma ${ }^{5}$ dos valores de PCS e LEC-MG.

Dois sítios por dente (vestibular e lingual) foram avaliados para as seguintes variáveis:

4. Índice de placa visível (AINAMO; BAY, 1975): foram considerados dentes com placa aqueles que apresentavam no mínimo um sítio (vestibular ou lingual) com placa visível a olho nú. Sítios com ou sem placa visível foram classificados como 0 ou 1 , respectivamente.

\footnotetext{
${ }^{2}$ Espelho $n^{\circ} \# 5$, Hu Friedy, Chicago, IL, USA

${ }^{3}$ PCPUNC - 15, Hu Friedy, Chicago, IL, USA

${ }^{4}$ Gracey Curettes 5/6, 11/12, 13/14, Hu Friedy, Chicago, IL, USA

${ }^{5} \mathrm{NCl}=\mathrm{PCS}+($ LEC-MG)
} 
5. Ausência/Presença de cálculo supra-gengival: cálculo supra-gengival foi definido como depósitos calcificados localizados em uma coroa exposta e/ou superfícies radiculares que se extenderem em até $1 \mathrm{~mm}$ abaixo da margem gengival livre (SUSIN, 2004).

Cárie dentária foi avaliada pela presença de cavidades em cada dente, e sua extenção foi expressa por meio do índice COD. O diagnóstico de Diabetes Mellitus foi avaliado pela determinação da glicemia capilar plasmática (GCP) casual, em mg/dL utilizando-se o dispositivo Accu-Check ${ }^{6}$, baseando-se no seguinte critério (THE EXPERT COMITTEE ON THE DIAGNOSIS AND CLASSIFICATION OF DIABETES MELLITUS, 2003) (Tabela 4.3).

Tabela 4.3 - Valores de glicose plasmática $(\mathrm{mg} / \mathrm{dL})$ para diagnóstico de Diabetes Mellitus e seus estágios pré-clínicos

\begin{tabular}{cccc}
\hline Categorias & Jejum $^{\mathbf{1}}$ & $\begin{array}{c}\text { 2h após 75g } \\
\text { glicose }\end{array}$ & Casual $^{\mathbf{2}}$ \\
\hline $\begin{array}{c}\text { Glicemia de } \\
\text { jejum alterada }\end{array}$ & $>100 \mathrm{e}<126$ & $<140$ (se realizada) \\
\hline $\begin{array}{c}\text { Tolerância à } \\
\text { glicose diminuída }\end{array}$ & $<126$ & $\geq 140 \mathrm{e}<200$ \\
\hline Diabetes mellitus & $\geq 126$ & $>200$ & \begin{tabular}{l}
$\geq 200$ (com sintomas $^{\text {clássicos) }}$ \\
\hline
\end{tabular}
\end{tabular}

${ }^{1} \mathrm{O}$ jejum é definido como a falta de ingestão calórica de no mínimo 8 horas.

2 Glicemia plasmática casual é definida como aquela realizada a qualquer hora do dia, sem observar o intervalo da última refeição.

${ }^{3}$ Os sintomas clássicos de Diabetes mellitus incluem poliúria, polidipsia e perda inexplicada de peso.

Nota: O diagnóstico de Diabetes mellitus deve sempre que possível ser confirmado pela repetição do teste em outro dia, a menos que haja hiperglicemia inequívoca com descompensação metabólica aguda ou sintomas óbvios de Diabetes mellitus. 
Em caso de indivíduos avaliados com GCP casual $\geq 200 \mathrm{mg} / \mathrm{dL}$, foi realizada a repetição do teste de glicemia no dia seguinte, com o indivíduo em questão em jejum, para confirmação do diagnóstico, caso valores de GCP $\geq 126 \mathrm{mg} / \mathrm{dL}$ fossem encontrados.

\subsection{Avaliação da reprodutibilidade das variáveis}

As entrevistas foram treinadas previamente à realização do estudo, por meio de um pré-teste do questionário, realizado em 18 indivíduos residentes na cidade de Paraty, com escolaridade e CSE semelhantes às encontradas na população alvo. As entrevistas por meio do questionário estruturado foram então aprimoradas quanto a uma linguagem mais adequada e permissiva. Das 24 questões inicialmente propostas, 3 foram eliminadas e uma foi modificada, devido à ausência de respostas confiáveis.

Alguns procedimentos de padronização foram empregados pelo entrevistador para garantir uma maior consistência dos dados obtidos. Dentre eles foram incluídos: exercício de uma atitude permissiva e amigável (BOWLING, 2005), aderência à seqüência estabelecida de questões; e uniformidade na elaboração das perguntas (BOWLING et al., 1999; SCHUMAN; PRESSER, 1981; SUSIN, 2004).

Durante a realização do estudo, as entrevistas foram repetidas em 15 indivíduos ( $7 \%$ da população de estudo), 7 dias após a realização da primeira entrevista. 0 coeficiente Kappa (HUBERT, 1977) para verificar a reprodutibilidade dos dados categóricos obtidos pelo questionário estruturado relacionados ao tabagismo, foi 0,86 . Ele foi realizado, já que estudos prévios (HELLER et al., 1998; PATRICK et al., 1994; SCOTT; 
PALMER; STAPLETON, 2001; SPIEKERMAN; HUJOEL; DEROUEN, 2003; WAGENKNECHT et al., 1992; WELLS et al., 1998; WOODWARD; TUNSTALL-PEDOE, 1992) revelaram que pode existir alta inconsistência dos dados obtidos com relação a esta variável, por meio de entrevista.

Antes da realização e 4 meses após o início do estudo, o examinador foi calibrado para realizar o exame clínico, sob as mesmas condições em que realizou a mensuração dos parâmetros clínicos. A concordância intra-examinador de $\mathrm{NCl}$ foi avaliada por exames duplicados em quadrantes contra-laterais de todos os dentes em 13 indivíduos da população no total ( $6 \%$ da população de estudo) escolhidos aleatoriamente. O exame era repetido 7 dias após o primeiro exame (BECK; LÖE, 1993). O coeficiente de correlação intra-classes (CCI) (SHROUT; FLEISS, 1979) em nível de sítio variou entre 0.93 e 0.95 , e em nível de indivíduo ( $\mathrm{NCl}$ médio) entre 0.98 e 0.99 . O coeficiente $K w$ em nível de indivíduo para prevalência de $\mathrm{NCl} \geq 5 \mathrm{~mm}$ e $\mathrm{NCl} \geq 7 \mathrm{~mm}$ foi igual a 1 .

Para avaliar a concordância dos resultados obtidos na determinação da GCP casual, o dispositivo Accu-Chek foi calibrado durante a realização do estudo por meio de reexame em 13 indivíduos da população ( 6\% da população de estudo), logo após da realização do primeiro exame. O coeficiente Kappa (HUBERT, 1977) para verificar a reprodutibilidade dos dados categóricos obtidos pelo dispositivo em questão foi igual a 1.

\subsection{Análise de dados}

\subsubsection{Armazenamento dos dados}


Os dados obtidos pelo exame clínico e pelas entrevistas foram transformados em dados eletrônicos após a coleta em campo, por meio do programa Epidata ${ }^{7}$ para Windows XP. Os dados eletrônicos foram impressos e então comparados com os dados originais em papel, para correção de possíveis erros de digitação.

\subsubsection{Análise estatística}

Após a coleta dos dados, as relações entre os valores foram estudadas e descritas por meio do programa Stata $9.0^{8}$ para Windows, para a descrição da distribuição e freqüência das diferentes variáveis.

A prevalência de perda clínica de inserção foi definida pela porcentagem de indivíduos que apresentaram no mínimo 1 sítio com uma determinada condição (ALBANDAR; BRUNELLE; KINGMAN, 1999; BROWN; BRUNELLE; KINGMAN, 1996; SUSIN et al., 2004b). A extensão foi descrita como porcentagem de sítios por indivíduo com uma determinada condição (BROWN; BRUNELLE; KINGMAN, 1996) e como número de sítios por indivíduo com uma determinada condição. Todas estas condições foram descritas para $\mathrm{NCl} \geq 1 \mathrm{~mm}, \geq 3 \mathrm{~mm}, \geq 5 \mathrm{~mm}$ e $\geq 7 \mathrm{~mm}$. A severidade foi considerada, após a coleta dos dados, como moderada $(\geq 5 \mathrm{~mm})$ e severa $(\geq 7 \mathrm{~mm})$, respectivamente.

\footnotetext{
$\overline{7}$ Epidata Entry version 2.0, Odense, Denmark.

${ }^{8}$ Stata versão 9.0 para Windows, Stata Corporation, College Station, TX, USA.
} 
Para explorar e quantificar a associação entre os candidatos de risco demográficos, comportamentais e biológicos com a prevalência de perda clínica de inserção moderada $(\mathrm{NCl} \geq 5 \mathrm{~mm})$, e severa $(\mathrm{NCl} \geq 7 \mathrm{~mm})$ nesta população, foram realizados uma série de análises de regressão logística multivariável (procedimento logit no STATA).

As variáveis independentes ou preditores candidatos considerados para inclusão na análise de regressão logística incluíram:

1) Idade (12-19 / 20-29 / 30 ou mais anos);

2) Gênero (masculino / feminino);

3) Presença de renda monetária (não / sim);

4) Anos de escolaridade ( $\leq 4$ anos / > 4 anos);

5) Analfabetismo (não / sim);

6) Presença de tratamento odontológico urgencial (não / sim);

7) Proporção de sítios por indivíduo com placa visível (<75\% / $\geq 75 \%$ );

8) Proporção de sítios por indivíduo com cálculo supra-gengival (<20\% / 20-50\% / $>50 \%)$

9) Presença de Diabetes Mellitus (não / sim);

10) Fumante (não / sim). Foram considerados não-fumantes os indivíduos que relataram fumar menos que 100 cigarros durante toda a vida; fumantes e exfumantes foram incluídos na mesma categoria. Os itens utilizados pelos fumantes incluíram cigarros comuns e cigarros de palha, e em poucos casos cannabis e cachimbos.

Todos os candidatos de risco que foram associados com os desfechos descritos a $p<0.25$, na análise de regressão univariável, foram incluídos no modelo multivariável (HOSMER; LEMESHOW, 2000). Os candidatos foram removidos do modelo um a um, até 
o teste de razão log-likelihood (HOSMER; LEMESHOW, 2000) indicar que mais nenhuma variável pôde ser removida. Uma variável foi considerada fator de confusão se sua remoção do modelo multivariável significou em mudanças maiores do que $15 \%$ no coeficiente $\beta$. Interações biologicamente plausíveis foram avaliadas. $O$ intervalo de confiança aplicado foi de 95\%. 


\section{RESULTADOS}

Um total de 264 indivíduos foram elegíveis para a participação neste estudo (Tabela 5.1). Destes 264 indivíduos, 214 (81,8\%) foram examinados e receberam os exames clínicos completos (Figura 5.1). Dos 50 indivíduos não-respondentes, 12 (24\%) foram entrevistados, porém se recusaram a participar dos exames clínicos, 10 (20\%) recusaram participar tanto da entrevista quanto dos exames clínicos, e 28 (56\%) não estavam presentes em suas residências no momento da realização dos exames. A maioria dos não-respondentes foi representada por indivíduos do gênero masculino na faixa etária de 20-29 anos, e a razão provável desta representatividade foi a constante ausência destes indivíduos devido ao trabalho de pesca. A Tabela 5.1 mostra a distribuição final da população do estudo de acordo com idade e gênero.

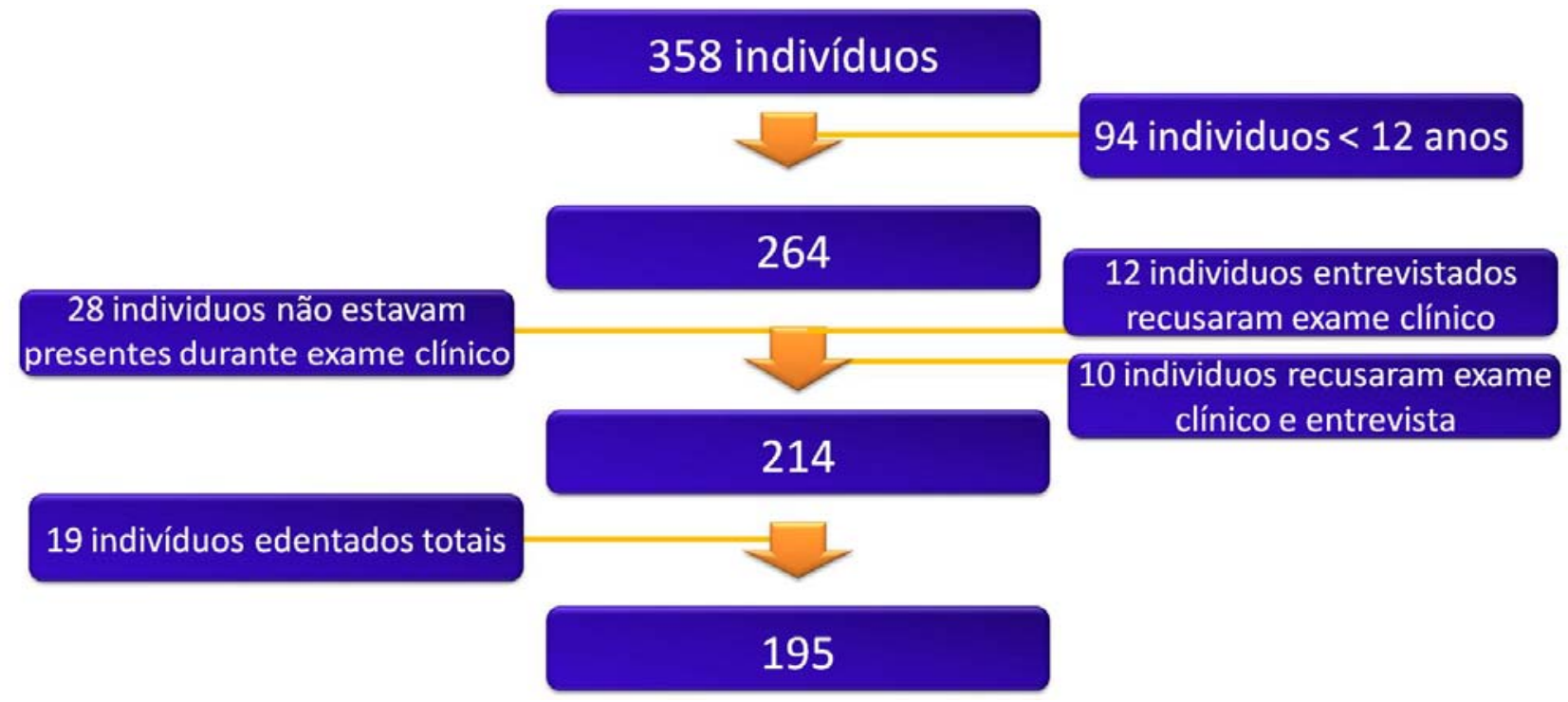

Figura 5.1 - População alvo e número final de indivíduos que receberam exame periodontal completo 
Tabela 5.1 - Distribuição da população de estudo de acordo com idade e gênero

\begin{tabular}{c|c|c|c|c|c|c}
\hline \multicolumn{7}{c|}{ POPULAÇÃO DO ESTUDO } \\
\multirow{2}{*}{$\begin{array}{c}\text { Idade } \\
\text { (anos) }\end{array}$} & \multicolumn{2}{|c|}{ Masculino } & \multicolumn{2}{|c|}{ Feminino } & \multicolumn{2}{c}{ Total } \\
\cline { 2 - 7 } & $\mathrm{N}$ & $\%$ & $\mathrm{~N}$ & $\%$ & $\mathrm{~N}$ & $\begin{array}{c}\text { \% da população } \\
\text { alvo }\end{array}$ \\
\hline $12-19$ & 21 & 53,8 & 18 & 46,2 & 39 & 78 \\
\hline $20-29$ & 31 & 50 & 31 & 50 & 62 & 74 \\
\hline $30-39$ & 22 & 55 & 18 & 45 & 40 & 89 \\
\hline $40-49$ & 14 & 51,8 & 13 & 48,2 & 27 & 82 \\
\hline $50+$ & 21 & 45,7 & 25 & 54,3 & 46 & 88 \\
\hline Total & 109 & 51 & 105 & 49 & 214 & 81 \\
\hline
\end{tabular}

Dezenove indivíduos eram edentados totais ( $8,88 \%$ da população alvo), correspondendo a $23 \%$ e $48 \%$ das mulheres das faixas etárias de $40-49$ anos e 50 ou mais anos, respectivamente (Tabela 5.2). O número médio de dentes presentes entre os indivíduos dentados foi menor nos grupos etários mais velhos (Figuras 5.2 e 5.3). Também foi bem menor entre os indivíduos do gênero feminino, que retinham apenas poucos dentes entre a $5^{\mathrm{a}}$ e $6^{\mathrm{a}}$ década de vida (Figura 5.3). A distribuição e freqüência de dentes perdidos e não-erupcionados, por tipo de elemento dental e faixa etária, é descrita na Figura 5.4 (valores negativos no eixo $x$ referem-se a dentes mandibulares).

A prevalência e extensão de cárie dentária, expressa pela média de dentes cariados e obturados, apresentaram-se relativamente uniformes entre os grupos etários jovens, porém menos extensa entre os grupos etários mais velhos. Entretanto, quando o índice COD foi expresso como porcentagem de dentes afetados, um aumento significativo na proporção de COD foi verificado com o aumento da idade nas mulheres (Tabela 5.2). 
Tabela 5.2 - Frequência de edentulismo e número médio de dentes presentes, cariados ou obturados, em indivíduos dentados por idade e gênero

\begin{tabular}{|c|c|c|c|c|c|c|}
\hline \multirow[b]{2}{*}{$\begin{array}{l}\text { Idade } \\
\text { (anos) }\end{array}$} & \multirow[b]{2}{*}{ Gênero } & \multirow[b]{2}{*}{$\mathbf{N}$} & \multicolumn{4}{|c|}{ Exame clínico dental } \\
\hline & & & $\begin{array}{c}\% \\
\text { edentulismo }\end{array}$ & $\begin{array}{c}\mathbf{n}^{\circ} \text { médio de } \\
\text { dentes } \\
\text { [IC 95\%] }\end{array}$ & $\begin{array}{l}\text { COD Médio } \\
\text { [IC 95\%] }\end{array}$ & $\begin{array}{l}\text { \% COD } \\
\text { Média }\end{array}$ \\
\hline \multirow[t]{2}{*}{$12-19$} & Meninos & 21 & 0 & $25,7[24,4 ; 27,0]$ & $4,0[2,8 ; 5,1]$ & 15,3 \\
\hline & Meninas & 18 & 0 & $26,3[25,5 ; 27,2]$ & $4,5[2,8 ; 6,2]$ & 16,9 \\
\hline \multirow[t]{2}{*}{$20-29$} & Homens & 31 & 0 & $24,6[23,8 ; 25,5]$ & $5,2[3,6 ; 6,7]$ & 21,4 \\
\hline & Mulheres & 31 & 0 & $24,8[23,4 ; 26,2]$ & $5,3[3,9 ; 6,7]$ & 21,4 \\
\hline \multirow[t]{2}{*}{$30-39$} & Homens & 22 & 0 & $21,6[19,5 ; 23,7]$ & $4,5[3,2 ; 5,9]$ & 24,6 \\
\hline & Mulheres & 18 & 0 & $16,9[14,2 ; 19,7]$ & $5,3[4,2 ; 6,5]$ & 32,7 \\
\hline \multirow[t]{2}{*}{$40-49$} & Homens & 14 & 0 & $20,2[17,3 ; 23,1]$ & $3,0[1,1 ; 4,9]$ & 14,4 \\
\hline & Mulheres & 13 & 23 & $12,3[7,7 ; 16,9]$ & $4,3[2,4 ; 6,2]$ & 43,7 \\
\hline \multirow[t]{2}{*}{$50+$} & Homens & 21 & 19 & $10,4[6,8 ; 13,9]$ & $2,0[1,0 ; 3,0]$ & 22,0 \\
\hline & Mulheres & 25 & 48 & $3,5[1,5 ; 5,4]$ & $2,3[1,6 ; 3,0]$ & 57,1 \\
\hline
\end{tabular}




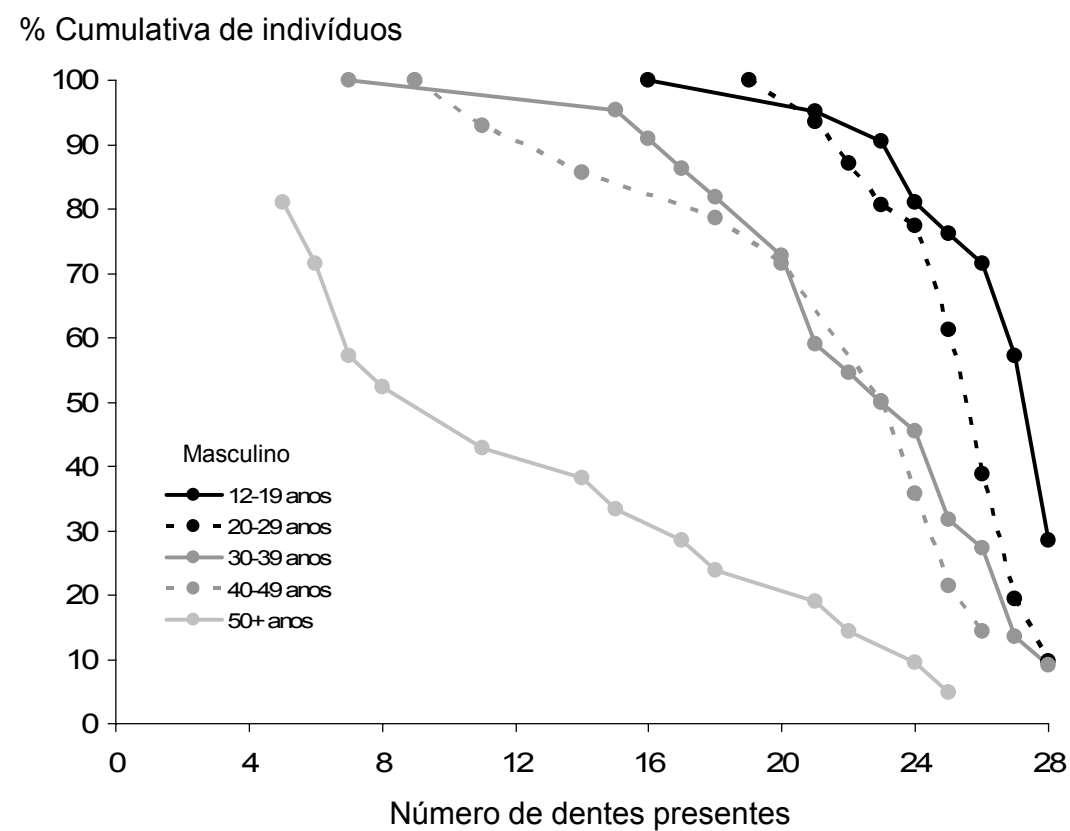

Figura 5.2 - Número de dentes presentes por indivíduo do gênero masculino, de acordo com a idade

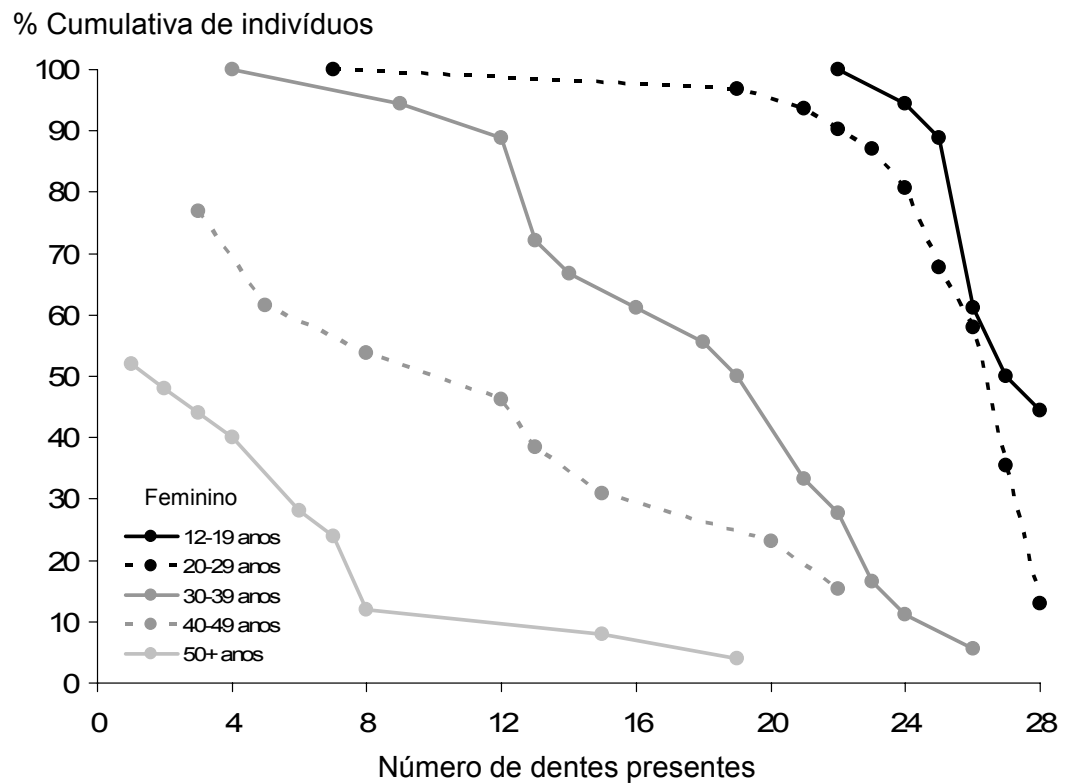

Figura 5.3 - Número de dentes presentes por indivíduo do gênero feminino, de acordo com a idade 


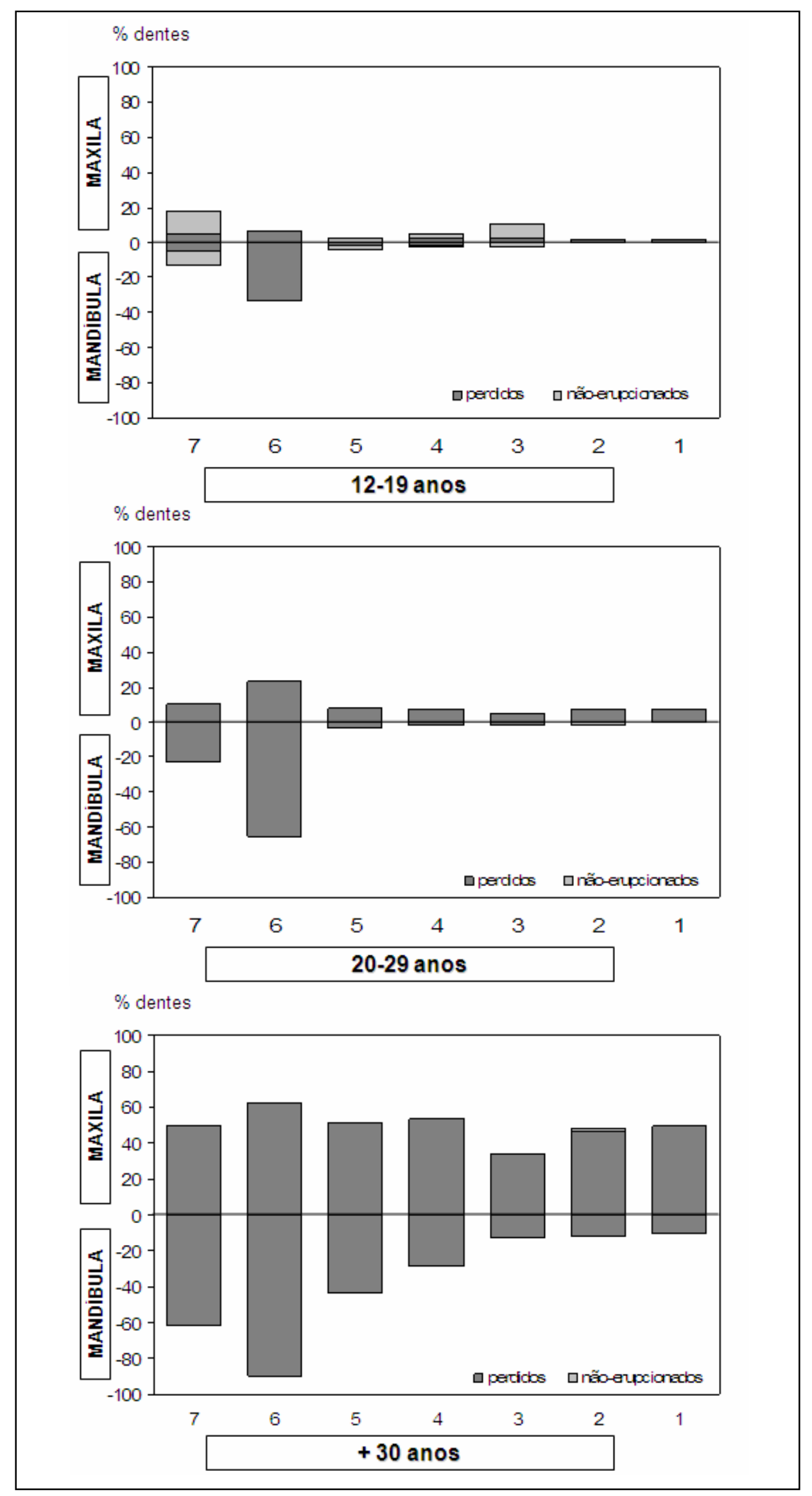

Figura 5.4 - Distribuição de dentes perdidos e não-erupcionados por tipo de elemento dental e faixa etária 
Figuras 5.5 a 5.8 e Tabela 5.3 mostram que $\mathrm{NCl} \geq 1 \mathrm{~mm}$ e $\geq 3 \mathrm{~mm}$ foram encontrados em todos os indivíduos examinados e em todos os grupos etários. $\mathrm{NCl} \geq$ $5 \mathrm{~mm}$ foi observado em $7,7 \%, 37,1 \%, 70 \%, 83,3 \%$ e $100 \%$ dos indivíduos dentados nos grupos etários de 12-19, 20-29, 30-39, 40-49 e 50 ou mais anos de idade, respectivamente; enquanto que $\mathrm{NCI} \geq 7 \mathrm{~mm}$ foi observado em $5,1 \%, 8,1 \%, 20 \%, 66,7 \%$ e 83,3\% dos indivíduos nos grupos etários de 12-19, 20-29, 30-39, 40-49 e 50 ou mais anos de idade, respectivamente.

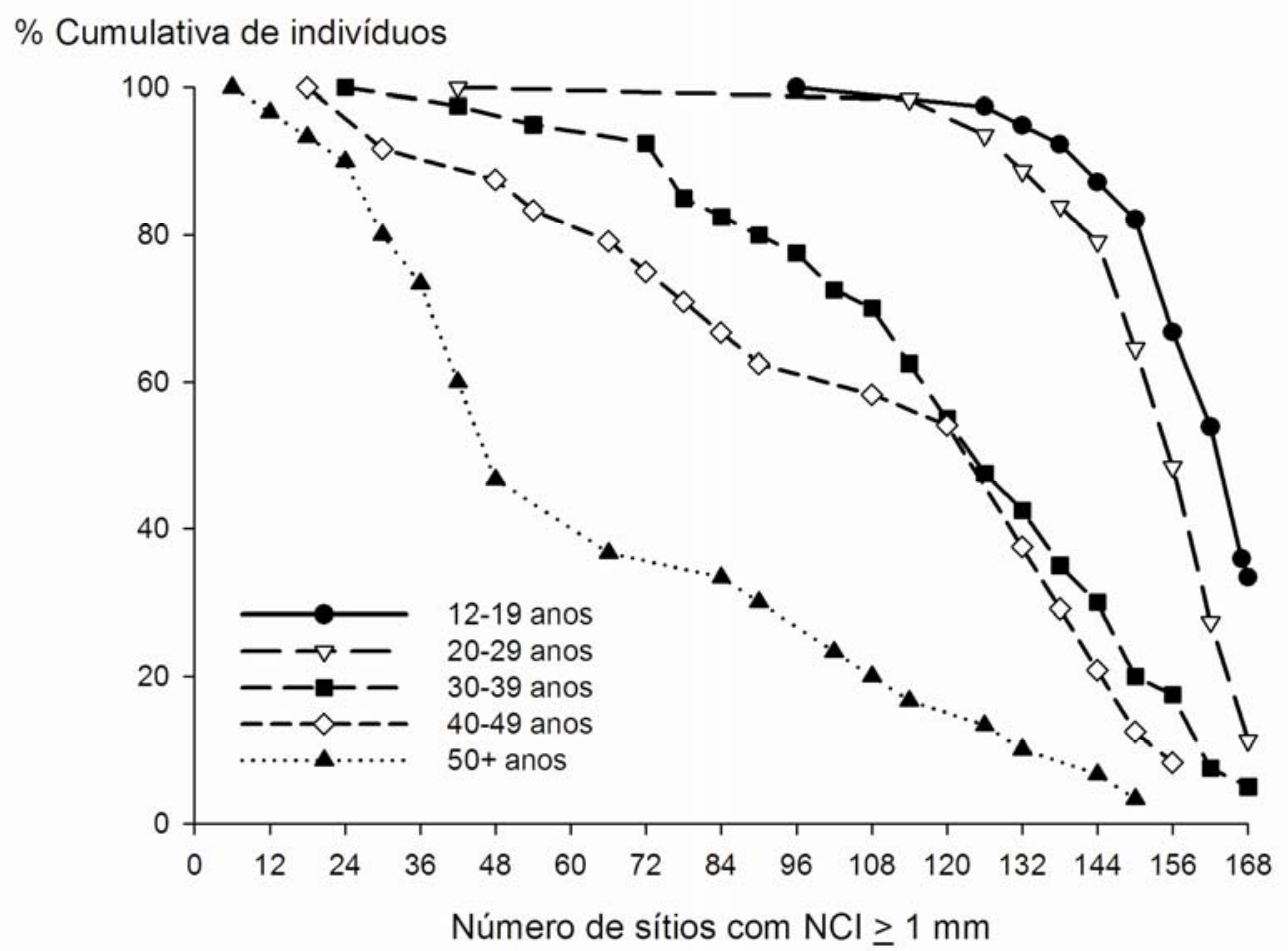

Figura 5.5 - Freqüência cumulativa de número de sítios por indivíduo com $\mathrm{NCl} \geq 1 \mathrm{~mm}$, de acordo com a idade 
$\%$ Cumulativa de indivíduos

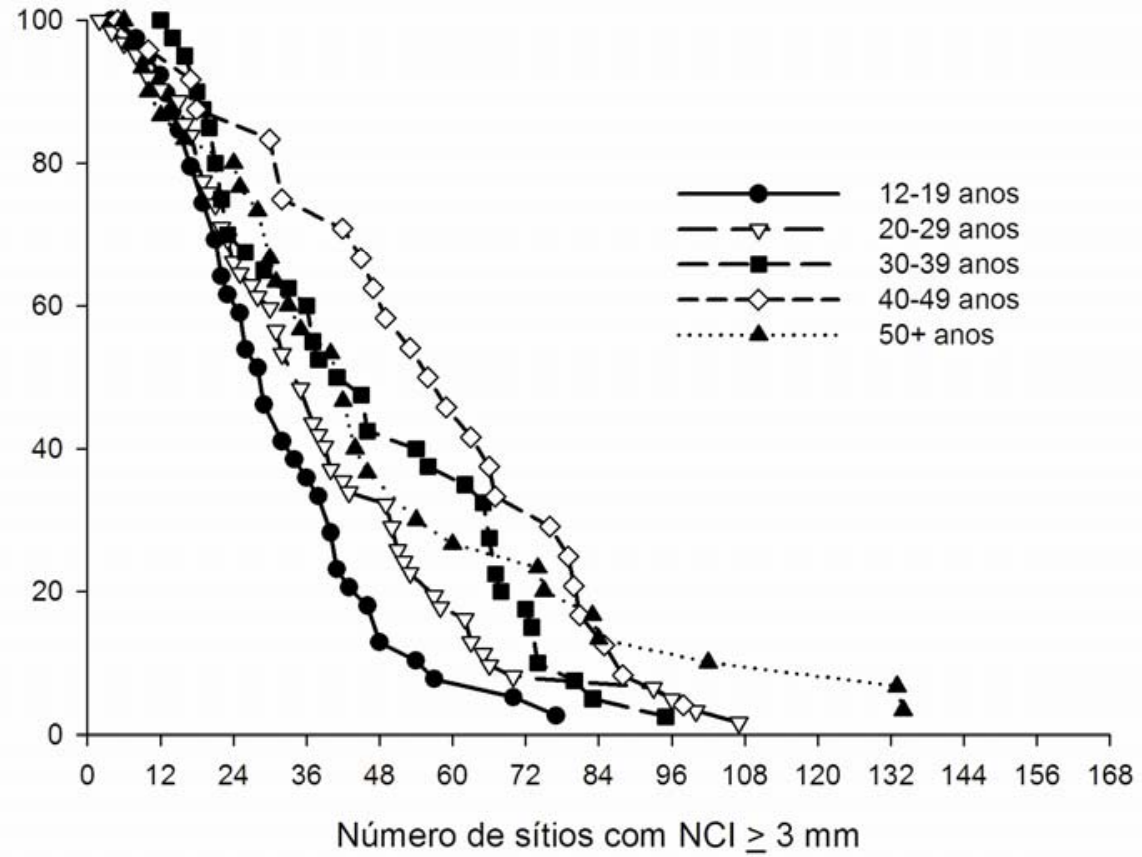

Figura 5.6 - Freqüência cumulativa de número de sítios por indivíduo com $\mathrm{NCl} \geq 3 \mathrm{~mm}$, de acordo com a idade

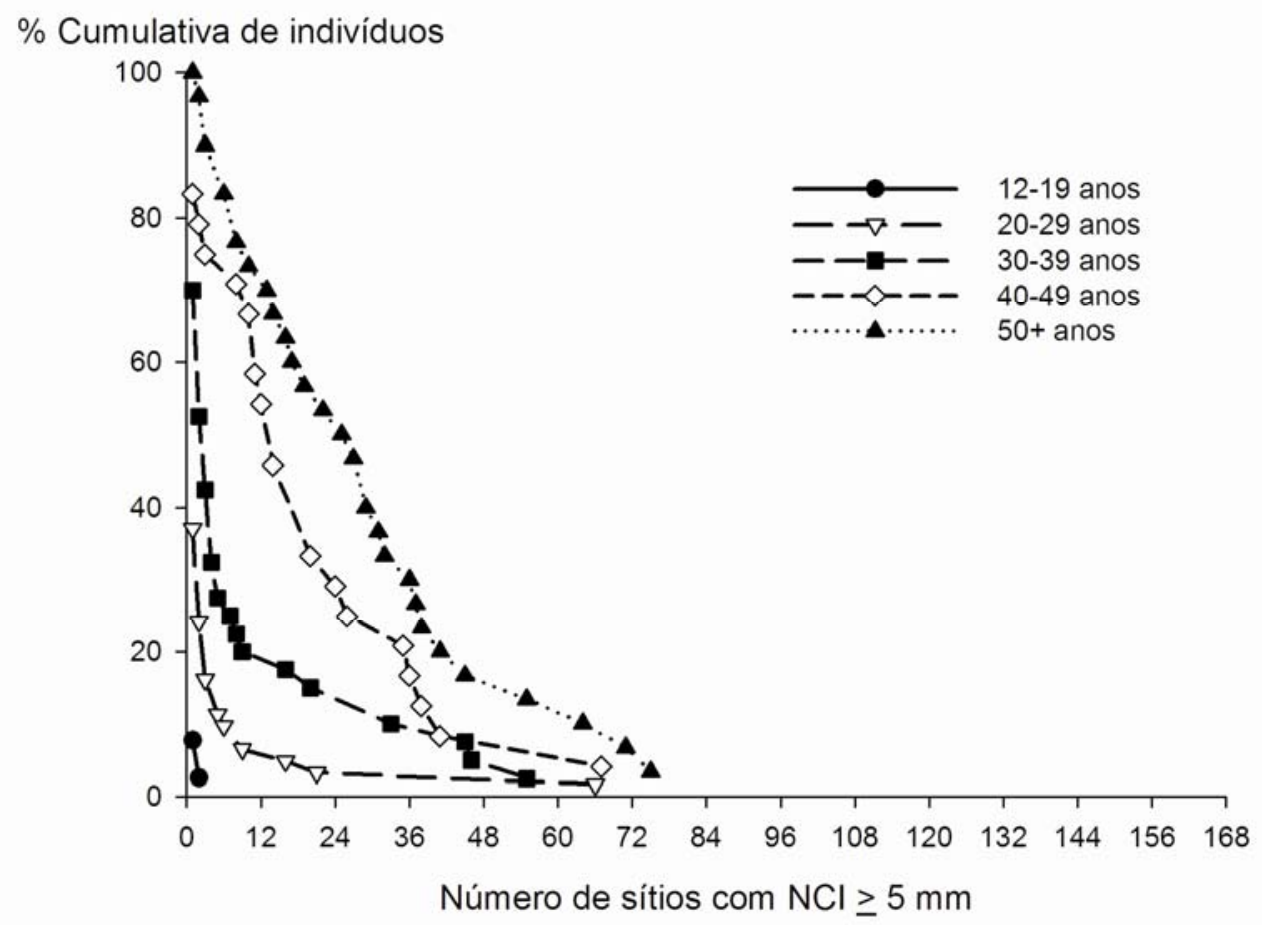

Figura 5.7 - Freqüência cumulativa de número de sítios por indivíduo com $\mathrm{NCl} \geq 5 \mathrm{~mm}$, de acordo com a idade 
$\%$ Cumulativa de indivíduos

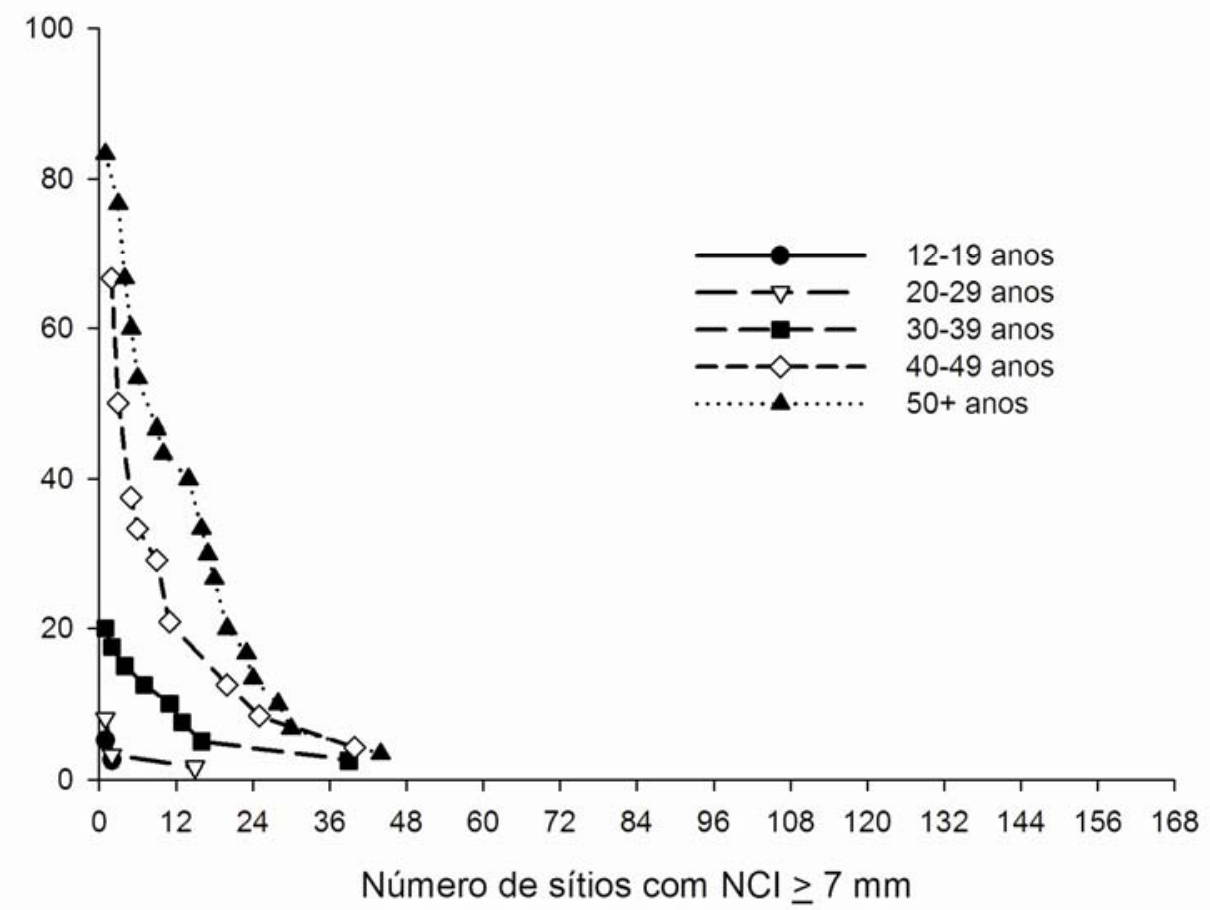

Figura 5.8 - Freqüência cumulativa de número de sítios por indivíduo com $\mathrm{NCI} \geq 7 \mathrm{~mm}$, de acordo com a idade

O número de sítios afetados variou, sendo que para $\mathrm{NCI} \geq 1 \mathrm{~mm}$ o número de sítios afetados decresceu com o aumento da idade. Já para $\mathrm{NCl} \geq 3 \mathrm{~mm}$, o gradiente de idade foi menos marcante e, para $\mathrm{NCl} \geq 5 \mathrm{~mm}$ e $\geq 7 \mathrm{~mm}$ o gradiente etário foi tal que o aumento da idade contribuiu para um aumento de sítios afetados. No entanto, quando a extensão foi descrita como porcentagem de sítios afetados por indivíduo, um gradiente etário claramente definido foi expresso para $\mathrm{NCl} \geq 3 \mathrm{~mm}, 5 \mathrm{~mm}$ e $7 \mathrm{~mm}$, tal que o aumento da idade contribuiu para uma maior porcentagem de sítios afetados (Tabela 5.3). 
Tabela 5.3 - Prevalência (\%) e extensão de $\mathrm{NCl} \geq 3 \mathrm{~mm}, \mathrm{NCl} \geq 5 \mathrm{~mm}$ e $\mathrm{NCl} \geq 7 \mathrm{~mm}$ de acordo com a idade e gênero. [ ] denota o IC de 95\% para a extensão

\begin{tabular}{c|c|c|c|c|c|c|c|c|c|}
\hline Idade & \multicolumn{3}{|c|}{ NCI $\geq 3$ mm } & \multicolumn{3}{c|}{ NCI $\geq 5$ mm } & \multicolumn{3}{c|}{ NCI $\geq 7$ mm } \\
(anos) & $\%$ & Extensão & IC 95\% & $\%$ & Extensão & IC 95\% & $\%$ & Extensão & IC 95\% \\
\hline $12-19$ & 100 & 60,8 & {$[53,6 ; 68,1]$} & 7,7 & 4,2 & {$[3,6 ; 4,8]$} & 5,1 & 3,9 & {$[3,5 ; 4,4]$} \\
\hline $20-29$ & 100 & 65,9 & {$[59,8 ; 72,0]$} & 37,1 & 14,9 & {$[6,3 ; 23,5]$} & 8,1 & 13,6 & {$[-6,0 ; 33,1]$} \\
\hline $30-39$ & 100 & 78,2 & {$[71,4 ; 85,0]$} & 70,0 & 29,0 & {$[17,6 ; 40,4]$} & 20,0 & 38,2 & {$[13,6 ; 62,9]$} \\
\hline $40-49$ & 100 & 89,2 & {$[83,2 ; 95,2]$} & 83,3 & 51,0 & {$[37,8 ; 64,1]$} & 66,7 & 28,6 & {$[15,2 ; 41,9]$} \\
\hline $50+$ & 100 & 97,2 & {$[94,5 ; 99,9]$} & 100 & 76,9 & {$[65,9 ; 88,0]$} & 83,3 & 52,4 & {$[40,6 ; 64,1]$} \\
\hline
\end{tabular}

Entre os indivíduos adultos (30 ou mais anos) e adultos-jovens (20-29 anos), os dentes mais afetados por perda de inserção severa $(\mathrm{NCl} \geq 7 \mathrm{~mm})$ foram os $1^{\circ}$ molares superiores e os incisivos centrais inferiores (Figura 5.9 e 5.10). Na faixa etária de 12-19, esta distribuição foi bem diferente, sendo que o $2^{\circ}$ pre-molar inferior representou o dente mais afetado por $\mathrm{NCl} \geq 7 \mathrm{~mm}$ (Figura 5.11). Os valores negativos no eixo $x$ referem-se aos dentes mandibulares. 


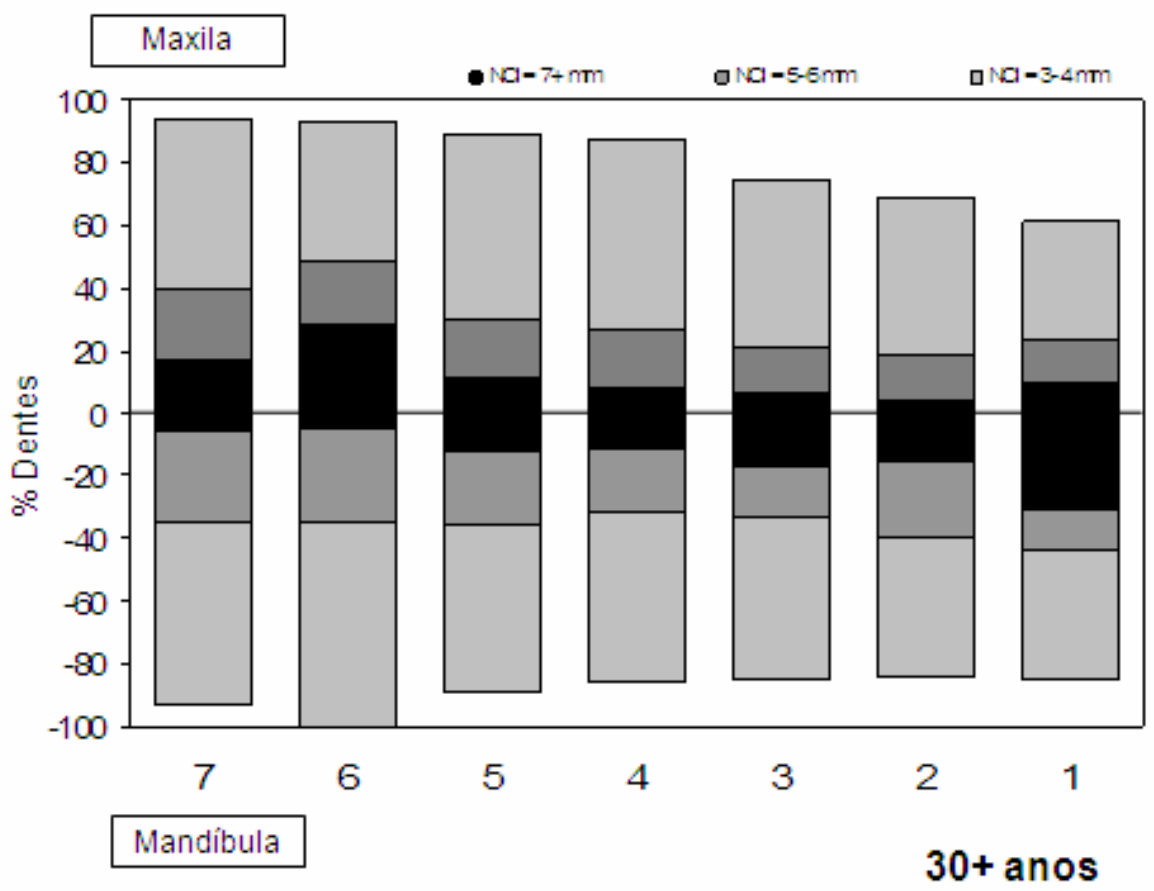

Figura 5.9 - Porcentagem de dentes afetados por $\mathrm{NCl}$ em suas diferentes severidades por tipo de dente na maxila e mandíbula nos indivíduos adultos

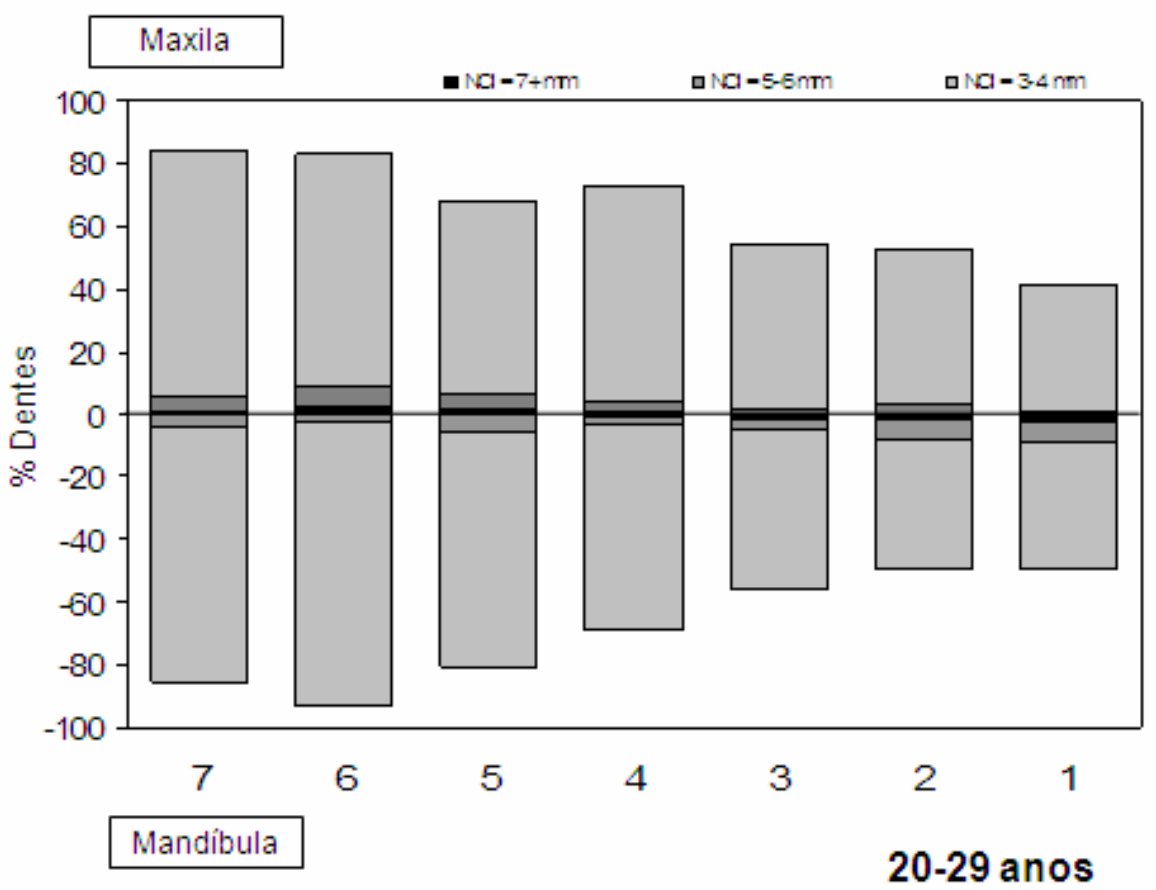

Figura 5.10 - Porcentagem de dentes afetados por $\mathrm{NCl}$ em suas diferentes severidades por tipo de dente na maxila e mandíbula nos indivíduos adultos-jovens (20-29 anos) 


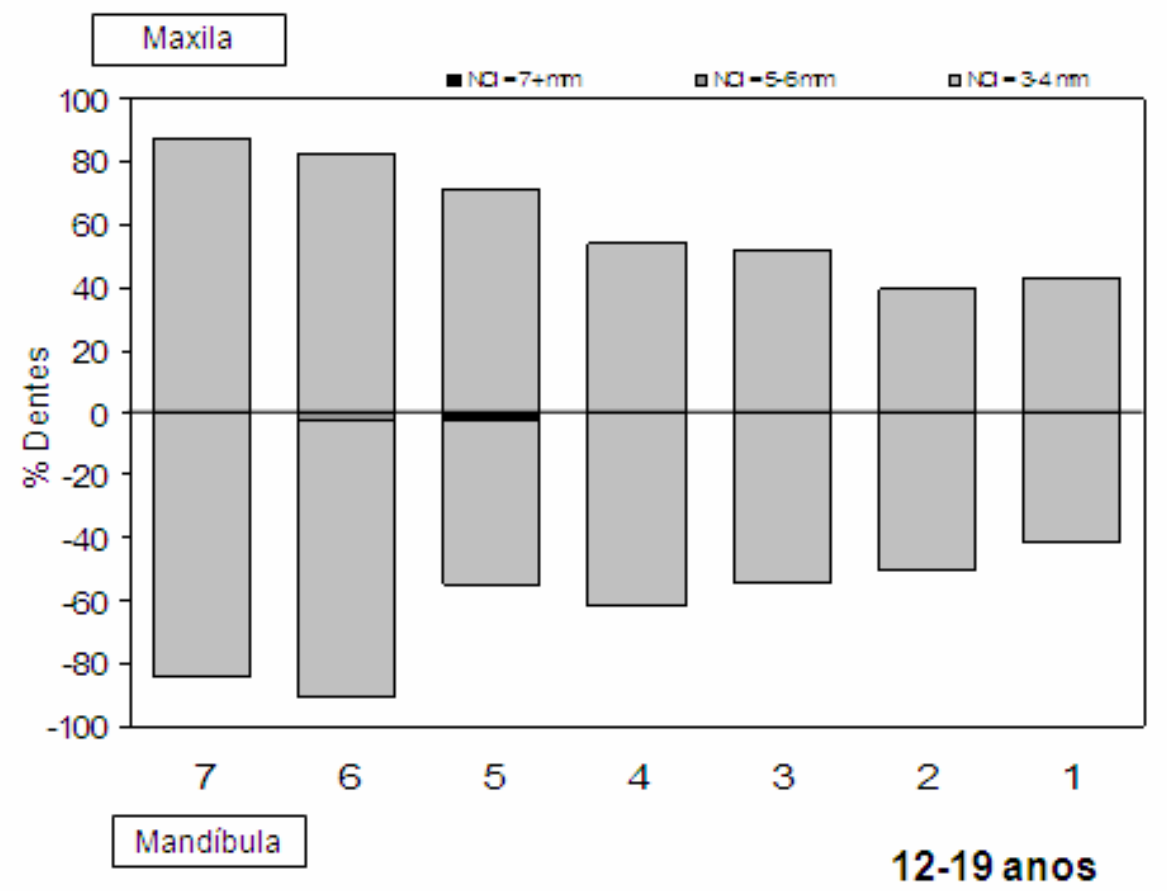

Figura 5.11 - Porcentagem de dentes afetados por $\mathrm{NCl}$ em suas diferentes severidades por tipo de dente na maxila e mandíbula nos indivíduos de 12 a 19 anos

A Figura 5.12 mostra que tanto placa quanto cálculo supra-gengival foram altamente prevalentes e extensos em todos os grupos etários. Tanto para placa quanto para cálculo supra-gengival, um gradiente de idade ficou claramente definido, sendo que um aumento na idade contribuiu para uma maior proporção de sítios afetados.

A distribuição da freqüência dos preditores ou variáveis dependentes com relação à prevalência e extensão de $\mathrm{NCl} \geq 5 \mathrm{~mm}$ e $\geq 7 \mathrm{~mm}$, e sua prevalência na população de estudo dentada está representada na Tabela 5.4. Cerca de $38 \%$ da população constituiase de fumantes ou ex-fumantes, sendo que a intensidade média foi de aproximadamente 6 cigarros por dia com uma duração média de 8 anos. 
$\%$ Cumulativa de indivíduos

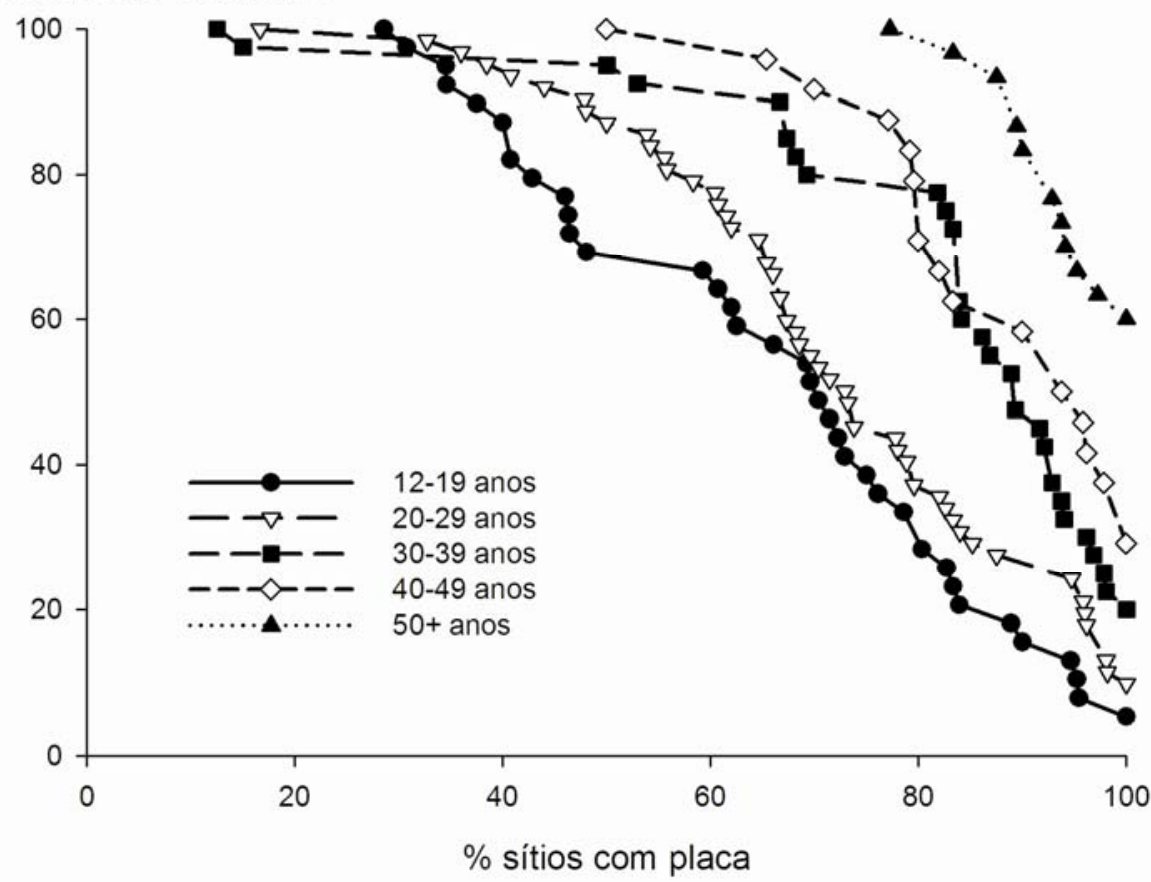

$\%$ Cumulativa de indivíduos

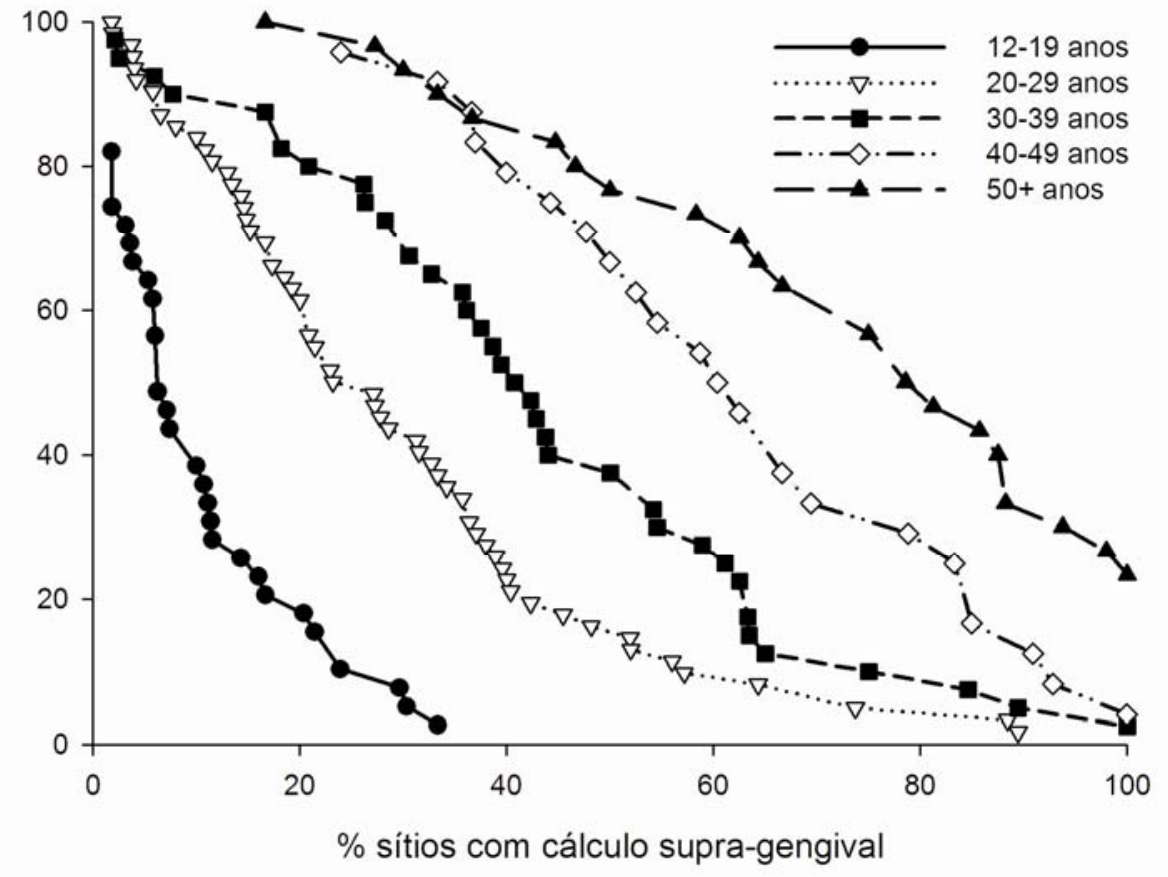

Figura 5.12 - Distribuição da freqüência cumulativa de indivíduos de acordo com a proporção de sítios com placa visível e cálculo supra-gengival 
Tabela 5.4 - Distribuição dos preditores candidatos demográficos, ambientais e biológicos com relação à prevalência e extensão de $\mathrm{NCl} \geq 5 \mathrm{~mm}$ e $\geq 7 \mathrm{~mm}$

\begin{tabular}{|c|c|c|c|c|c|}
\hline & & \multicolumn{2}{|c|}{ Prevalência } & \multicolumn{2}{|c|}{ Extensão (IC 95\%) } \\
\hline \multicolumn{2}{|c|}{ Preditor } & $\mathrm{NCl} \geq 5 \mathrm{~mm}$ & $\mathrm{NCl} \geq 7 \mathrm{~mm}$ & $\mathrm{NCl} \geq 5 \mathrm{~mm}$ & $\mathrm{NCl} \geq 7 \mathrm{~mm}$ \\
\hline \multirow{3}{*}{$\begin{array}{l}\text { Idade } \\
\text { (anos) }\end{array}$} & $\begin{array}{l}12-19 \\
n=39\end{array}$ & $7,7 \%$ & $5,1 \%$ & $\begin{array}{c}4,2 \% \\
(3,6 ; 4,8)\end{array}$ & $\begin{array}{c}3,9 \% \\
(3,5 ; 4,4)\end{array}$ \\
\hline & $\begin{array}{l}20-29 \\
n=62\end{array}$ & $37,1 \%{ }^{\dagger}$ & $8,1 \%$ & $\begin{array}{c}14,9 \%^{\dagger} \\
(6,3 ; 23,5)\end{array}$ & $\begin{array}{c}13,6 \% * \\
(-6,0 ; 33,1)\end{array}$ \\
\hline & $\begin{array}{c}30+ \\
n=94\end{array}$ & $83,0 \%^{\dagger}$ & $52,1 \%{ }^{\dagger}$ & $\begin{array}{c}53,1 \%^{\dagger} \\
(44,9 ; 61,3)\end{array}$ & $\begin{array}{c}42,3 \%{ }^{*} \\
(33,5 ; 51,1)\end{array}$ \\
\hline \multirow[t]{2}{*}{ Gênero } & $\begin{array}{c}\text { Masculino } \\
n=105\end{array}$ & $59,1 \%$ & $34,3 \%$ & $\begin{array}{c}42,7 \% \\
(33,3 ; 52,1)\end{array}$ & $\begin{array}{c}33,6 \% \\
(24,4 ; 42,9) \\
\end{array}$ \\
\hline & $\begin{array}{c}\text { Feminino } \\
\mathrm{n}=90\end{array}$ & $46,7 \%$ & $22,2 \%$ & $\begin{array}{c}43,9 \% \\
(32,5 ; 55,4)\end{array}$ & $\begin{array}{c}46,8 \% \\
(30,8 ; 62,9) \\
\end{array}$ \\
\hline \multirow{2}{*}{$\begin{array}{c}\text { Recebeu } \\
\text { tratamento } \\
\text { odontológico? } \\
\text { (urgências) }\end{array}$} & $\underset{n=119}{\operatorname{Sim}}$ & $52,1 \%$ & $25,2 \%$ & $\begin{array}{c}41,8 \% \\
(32,1 ; 51,6) \\
\end{array}$ & $\begin{array}{c}43,3 \% \\
(31,2 ; 55,4) \\
\end{array}$ \\
\hline & $\begin{array}{l}\text { Não } \\
n=76\end{array}$ & $55,3 \%$ & $34,2 \%$ & $\begin{array}{c}45,3 \% \\
(34,5 ; 56,0)\end{array}$ & $\begin{array}{c}32,6 \% \\
(21,5 ; 43,8)\end{array}$ \\
\hline \multirow{2}{*}{$\begin{array}{l}\text { Fumante ou } \\
\text { ex-fumante? }\end{array}$} & $\operatorname{Sim}_{n=74}$ & $79,7 \%^{\dagger}$ & $59,5^{\dagger}$ & $\begin{array}{c}54,1 \%^{\dagger} \\
(44,5 ; 63,8) \\
\end{array}$ & $\begin{array}{c}36,9 \% \\
(27,7 ; 46,1) \\
\end{array}$ \\
\hline & $\begin{array}{c}\text { Não } \\
\mathrm{n}=121\end{array}$ & $37,2 \%$ & $9,9 \%$ & $\begin{array}{c}28,9 \% \\
(19,4 ; 38,4) \\
\end{array}$ & $\begin{array}{c}43,7 \% \\
(23,8 ; 63,5) \\
\end{array}$ \\
\hline \multirow{2}{*}{$\begin{array}{c}\text { Possui } \\
\text { Diabetes } \\
\text { mellitus? }\end{array}$} & $\begin{array}{l}\operatorname{Sim} \\
\mathrm{n}=2\end{array}$ & $100 \%$ & $50,0 \%$ & $\begin{array}{c}58,9 \% \\
(-22,5 ; 140,4)\end{array}$ & $\begin{array}{c}16,7 \% \\
-\end{array}$ \\
\hline & $\begin{array}{c}\text { Não } \\
n=193\end{array}$ & $52,9 \%$ & $28,5 \%$ & $\begin{array}{c}42,9 \% \\
(35,6 ; 50,2)\end{array}$ & $\begin{array}{c}38,7 \% \\
(30,3 ; 47,2)\end{array}$ \\
\hline \multirow{2}{*}{$\begin{array}{l}\text { Anos de } \\
\text { estudo }\end{array}$} & $\begin{array}{c}<4 \text { anos } \\
n=95\end{array}$ & $68,4 \%^{\dagger}$ & $42,1 \%$ * & $\begin{array}{c}50,6 \% \\
(41,3 ; 59,9)\end{array}$ & $\begin{array}{c}42,5 \% \\
(32,6 ; 52,4)\end{array}$ \\
\hline & $\begin{array}{c}\geq 4 \text { anos } \\
n=100\end{array}$ & $39,0 \%$ & $16,0 \%$ & $\begin{array}{c}30,9 \% \\
(20,4 ; 41,4)\end{array}$ & $\begin{array}{c}28,0 \% \\
(13,2 ; 42,7)\end{array}$ \\
\hline \multirow[t]{2}{*}{ Analfabeto? } & $\operatorname{Sim}_{n=58}$ & $84,5 \%{ }^{\dagger}$ & $58,6 \%{ }^{\dagger}$ & $\begin{array}{c}57,1 \%^{\dagger} \\
(46,7 ; 67,5)\end{array}$ & $\begin{array}{c}44,9 \%{ }^{*} \\
(34,3 ; 55,5)\end{array}$ \\
\hline & $\begin{array}{c}\text { Não } \\
n=137\end{array}$ & $40,2 \%$ & $16,1 \%$ & $\begin{array}{c}30,8 \% \\
(22,0 ; 39,7) \\
\end{array}$ & $\begin{array}{c}28,2 \% \\
(15,5 ; 40,9) \\
\end{array}$ \\
\hline \multirow{2}{*}{$\begin{array}{c}\text { Possui renda } \\
\text { monetária? }\end{array}$} & $\begin{array}{c}\operatorname{Sim} \\
\mathrm{n}=184\end{array}$ & $54,6 \%$ & $27,3 \%$ & $\begin{array}{c}39,7 \% \\
(1,5 ; 77,9)\end{array}$ & $\begin{array}{c}65,5 \% \\
(12,1 ; 118,9) \\
\end{array}$ \\
\hline & $\begin{array}{l}\text { Não } \\
n=11\end{array}$ & $53,3 \%$ & $28,8 \%$ & $\begin{array}{c}43,4 \% \\
(36,1 ; 50,8) \\
\end{array}$ & $\begin{array}{c}36,8 \% \\
(28,6 ; 45,1) \\
\end{array}$ \\
\hline \multirow{2}{*}{$\begin{array}{c}\text { \% sítios } \\
\text { Placa visível }\end{array}$} & $\begin{array}{l}<75 \% \\
n=72\end{array}$ & $19,4 \%$ & $5,6 \%$ & $\begin{array}{c}7,0 \% \\
(3,4 ; 10,5)\end{array}$ & $\begin{array}{c}3,8 \% \\
(3,6 ; 4,1)\end{array}$ \\
\hline & $\begin{array}{l}\geq 75 \% \\
n=123\end{array}$ & $73,2 \%{ }^{\dagger}$ & $42,3 \%^{\dagger}$ & $\begin{array}{c}48,9 \%^{\dagger} \\
(41,2 ; 56,5)\end{array}$ & $\begin{array}{c}41,0 \%{ }^{*} \\
(32,5 ; 49,6)\end{array}$ \\
\hline
\end{tabular}




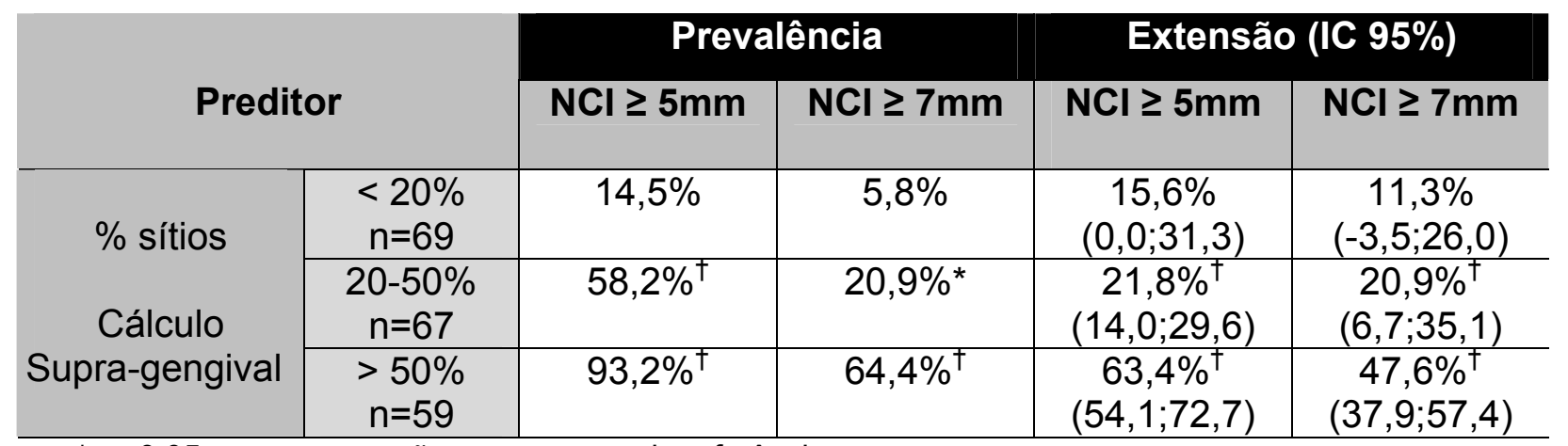

${ }^{*} p<0,05$, em comparação com o grupo de referência.

${ }^{\dagger} p<0,01$, em comparação com o grupo de referência.

A Tabela 5.5 mostra a análise de regressão logística univariável da associação entre cada uma das duas variáveis dependentes (prevalência de $\mathrm{NCl} \geq 5 \mathrm{~mm}$ e $\mathrm{NCl} \geq$ $7 \mathrm{~mm}$ ) e as variáveis independentes. Para a análise, a idade foi considerada como uma variável de três categorias para que pudesse ser possível a realização da análise de regressão logística multivariável. Para ambas as variáveis dependentes, a análise univariável sugeriu associação significativa com maior faixa etária (20 ou mais anos de idade para $\mathrm{NCl} \geq 5 \mathrm{~mm}$ e 30 ou mais anos de idade para $\mathrm{NCl} \geq 7 \mathrm{~mm}$ ), ser fumante ou exfumante, possuir menos de 4 anos de estudo, ser analfabeto, possuir mais que $75 \%$ de sítios com placa, e mais que $20 \%$ dos sítios com cálculo supra-gengival. A Tabela 5.6 mostra que idade adulta (30 ou mais anos de idade) $(\mathrm{OR}=11,4)$, ser fumante ou exfumante $(O R=2,4)$, possuir mais que $75 \%$ dos sítios com placa $(O R=2,8)$, e possuir altas porcentagens de sítios com cálculo supra-gengival ( $O R=2,9$ para $20-50 \%$ dos sítios e $\mathrm{OR}=10,6$ para mais que $50 \%$ dos sítios afetados) foram os fatores ou preditores associados positivamente com a presença de perda de inserção moderada no modelo de regressão logística multivariável final. O único preditor estatisticamente significante para a prevalência de perda de inserção severa no modelo final foi o tabagismo $[O R=8,2(3,4-$ 20)]. Entretanto, as variáveis independentes idade, \% de sítios com placa, e \% de sítios com cálculo foram mantidas no modelo como fatores de confusão. 
Tabela 5.5 - Análise de regressão logística univariável entre as variáveis dependentes prevalência de $\mathrm{NCI} \geq$ $5 \mathrm{~mm}$ e $\mathrm{NCl} \geq 7 \mathrm{~mm}$ e os preditores candidatos ou variáveis independentes demográficas, ambientais e biológicas

\begin{tabular}{|c|c|c|c|c|c|}
\hline \multirow[b]{2}{*}{ Preditor } & \multirow[b]{2}{*}{ Categorias } & \multicolumn{2}{|c|}{$\mathrm{NCl} \geq 5 \mathrm{~mm}$} & \multicolumn{2}{|c|}{$\mathrm{NCI} \geq 7 \mathrm{~mm}$} \\
\hline & & OR & IC 95\% & OR & IC 95\% \\
\hline \multirow{3}{*}{$\begin{array}{l}\text { Idade } \\
\text { (anos) }\end{array}$} & $12-19$ & ref & - & ref & - \\
\hline & $20-29$ & 7,1 & {$[2,0 ; 25,6]$} & 1,6 & {$[0,3 ; 8,8]$} \\
\hline & $30+$ & 58,5 & {$[16,0 ; 213,5]$} & 20,1 & {$[4,6 ; 88,4]$} \\
\hline \multirow[t]{2}{*}{ Gênero } & Masculino & ref & - & ref & - \\
\hline & Feminino & 0,6 & {$[0,3 ; 1,1]$} & 0,5 & {$[0,3 ; 1,0]$} \\
\hline \multirow{2}{*}{$\begin{array}{l}\text { Presença de } \\
\text { tratamento urgencial? }\end{array}$} & Não & ref & - & ref & - \\
\hline & Sim & 0,9 & {$[0,5 ; 1,6]$} & 0,6 & {$[0,3 ; 1,2]$} \\
\hline \multirow{2}{*}{$\begin{array}{l}\text { Fumante ou ex- } \\
\text { fumante? }\end{array}$} & Não & ref & - & ref & - \\
\hline & Sim & 6,6 & {$[3,4 ; 13,1]$} & 13,3 & {$[6,3 ; 28,4]$} \\
\hline \multirow{2}{*}{$\begin{array}{l}\text { GCP Casual } \\
\geq 200 \mathrm{mg} / \mathrm{dL} ?\end{array}$} & Não & - & - & ref & - \\
\hline & Sim & * & - & 2,5 & {$[0,2 ; 40,8]$} \\
\hline \multirow[t]{2}{*}{ Analfabeto? } & Não & ref & - & ref & - \\
\hline & Sim & 8,1 & {$[3,7 ; 17,9]$} & 7,4 & {$[3,7 ; 14,8]$} \\
\hline \multirow[t]{2}{*}{ Anos de estudo } & $>4$ & ref & - & ref & - \\
\hline & $\leq 4$ & 3,4 & {$[1,9 ; 6,1]$} & 3,8 & {$[1,9 ; 7,5]$} \\
\hline \multirow{2}{*}{$\begin{array}{c}\text { Presença de renda } \\
\text { monetária? }\end{array}$} & Não & ref & - & ref & - \\
\hline & Sim & 1,1 & {$[0,3 ; 3,6]$} & 0,9 & {$[0,2 ; 3,6]$} \\
\hline \multirow{2}{*}{$\begin{array}{c}\% \\
\text { Placa visível }\end{array}$} & $<75 \%$ & ref & - & ref & - \\
\hline & $\geq 75 \%$ & 11,3 & {$[5,6 ; 22,9]$} & 12,5 & {$[4,3 ; 36,3]$} \\
\hline \multirow{3}{*}{$\begin{array}{c}\% \\
\text { Cálculo } \\
\text { Supragengival }\end{array}$} & $<20 \%$ & ref & - & ref & - \\
\hline & $20-50 \%$ & 8,2 & {$[3,6 ; 18,8]$} & 4,3 & {$[1,3 ; 13,8]$} \\
\hline & $>50 \%$ & 81,1 & {$[24,0 ; 273,8]$} & 29,4 & {$[9,4 ; 92,1]$} \\
\hline
\end{tabular}

${ }^{*}$ não foi estimada pela presença de poucos valores positivos. 
Tabela 5.6 - Modelo final de regressão logística multivariável para as variáveis dependentes prevalência de $\mathrm{NCl} \geq 5 \mathrm{~mm}$ e $\mathrm{NCl} \geq 7 \mathrm{~mm}$

\begin{tabular}{|c|c|c|c|c|c|}
\hline \multirow[b]{2}{*}{ Preditor } & \multirow[b]{2}{*}{ Categorias } & \multicolumn{2}{|c|}{$\mathrm{NCl} \geq 5 \mathrm{~mm}$} & \multicolumn{2}{|c|}{$\mathrm{NCl} \geq 7 \mathrm{~mm}$} \\
\hline & & OR & IC 95\% & OR & IC 95\% \\
\hline \multirow{3}{*}{$\begin{array}{l}\text { Idade } \\
\text { (anos) }\end{array}$} & $12-19$ & ref & - & ref & - \\
\hline & $20-29$ & 3,5 & {$[0,9 ; 14,1]$} & 0.4 & {$[0,1 ; 3,2]$} \\
\hline & $30+$ & 11,4 & {$[2,7 ; 47,4]$} & 2.8 & {$[0,5 ; 17,4]$} \\
\hline \multirow{2}{*}{$\begin{array}{c}\text { Fumante ou ex- } \\
\text { fumante? }\end{array}$} & Não & ref & - & ref & - \\
\hline & Sim & 2,4 & ]1,0;6,0] & 8.2 & {$[3,4 ; 20,0]$} \\
\hline \multirow{2}{*}{$\begin{array}{c}\% \\
\text { Placa visível }\end{array}$} & $<75 \%$ & ref & - & ref & - \\
\hline & $>75 \%$ & 2,8 & {$[1,1 ; 7,1]$} & 2.4 & {$[0,6 ; 9,9]$} \\
\hline \multirow{3}{*}{$\begin{array}{c}\% \\
\text { Cálculo } \\
\text { Supragengival }\end{array}$} & $<20 \%$ & ref & - & ref & - \\
\hline & $20-50 \%$ & 2,9 & {$[1,1 ; 7,6]$} & 1.3 & {$[0,3 ; 6,0]$} \\
\hline & $>50 \%$ & 10,6 & {$[2,5 ; 44,8]$} & 4.1 & {$[0,8 ; 21,4]$} \\
\hline \multicolumn{2}{|c|}{ Hosmer-Lemeshow } & \multicolumn{2}{|c|}{$\mathrm{Chi}^{2}=6,25$} & \multicolumn{2}{|c|}{$\mathrm{Chi}^{2}=8,99$} \\
\hline \multicolumn{2}{|c|}{ Goodness-of-fit test } & \multicolumn{2}{|c|}{$d f=7$} & \multicolumn{2}{|c|}{$d f=7$} \\
\hline \multicolumn{2}{|c|}{ Statistic } & \multicolumn{2}{|c|}{$p=0,51$} & \multicolumn{2}{|c|}{$p=0,25$} \\
\hline \multicolumn{2}{|c|}{ ROC - Área sob a curva } & \multicolumn{2}{|c|}{0,91} & \multicolumn{2}{|c|}{0,90} \\
\hline
\end{tabular}




\section{DISCUSSÃO}

Os resultados do presente estudo demonstram que perda de inserção periodontal é altamente prevalente entre indivíduos jovens e adultos desta população brasileira isolada. No entanto, ela afetou apenas um número limitado de dentes. Nível clínico de inserção $\geq$ $1 \mathrm{~mm}$ e $\geq 3 \mathrm{~mm}$ foi encontrado em todos os indivíduos e todos os grupos etários, e mais da metade dos indivíduos adultos apresentaram no mínimo um dente com $\mathrm{NCl} \geq 7 \mathrm{~mm}$. A última observação entra em discordância com o fato de que apenas uma pequena fração de todas as populações apresenta prevalência de doença periodontal destrutiva severa (ALBANDAR; RAMS, 2002; BAELUM; FEJERSKOV; MANJI, 1988; RONDEROS; PIHLSTROM; HODGES, 2001).

A prevalência mundial das doenças periodontais destrutivas, em sua forma mais severa é reportada entre 5 a 20\% (ALBANDAR, 2002; AAP, 2005). Entretanto, as disparidades encontradas entre populações podem, em parte, ser atribuídas à falta de padronização com relação à metodologia, e ao critério de avaliação de doença adotado em cada um destes estudos (OPPERMANN et al., 2005).

Outro fator de extrema importância, que também deve ser levado em consideração, é o efeito relacionado às marcantes perdas dentais em indivíduos com periodontite severa, que poderiam atuar para uma redução na sua prevalência devido a exclusões relacionadas a condições de edentulismo (ALBANDAR; RAMS, 2002). Entretanto, os altos valores de prevalência e extensão de cárie dentária encontrados na população estudada, e o fato do padrão de distribuição das perdas dentárias possuírem alta semelhança com 
os padrões de distribuição de cárie dentária podem indicar que estes indivíduos perderam seus dentes, na maioria das situações, por cárie dentária e não por doenças periodontais.

Nesta última década, têm surgido evidências convincentes de que a susceptibilidade às infecções microbianas possa ser determinada, em parte, pelo genótipo do hospedeiro (HODGE; MICHALOWICZ, 2001), além de fatores ambientais, comportamentais e biológicos. Com relação à necessidade de coleta de dados para este objetivo, populações encontradas nas Américas do Sul e Central representam uma oportunidade para estudar populações que, até certo grau, permanecem geograficamente, culturalmente e geneticamente isoladas e que, portanto, podem analisar a importância de fatores genéticos na susceptibilidade de doenças ou condições (DOWSETT et al., 2001), principalmente nesta população, que apresentou consangüinidade entre os indivíduos. Estes princípios têm sido aplicados no entendimento da susceptibilidade individual a outras doenças sistêmicas de origem microbiana, tais como a tuberculose, a malária e a lepra (ABEL; DESSEIN, 1998; STIRNADEL et al., 1999), e também podem ser aplicados no estudo das doenças periodontais destrutivas.

Existe pouca informação sobre a ocorrência de doenças periodontais em países em desenvolvimento, e os dados são particularmente esparsos para os países da América Latina, dentre eles, o Brasil (GJERMO et al., 2002; SUSIN et al., 2004b). Dos poucos levantamentos epidemiológicos conduzidos no Brasil e em outras populações isoladas, a maioria utilizou como instrumento o Índice Periodontal Comunitário de Necessidade de Tratamento (CPITN) (AINAMO et al., 1982) (ARANTES; SANTOS; COIMBRA JR, 2001; GALATI, 2003), que apresenta severas limitações como ferramenta para avaliação da prevalência, extensão e severidade das doenças periodontais destrutivas (BAELUM; PAPAPANOU, 1996); ou o Índice Periodontal de Russell (RUSSELL, 1967) (DONNELLY 
et al., 1977; NISWANDER, 1967; TUMANG; PIEDADE, 1968). Outros estudos utilizaramse de amostras de conveniência (ALBANDAR; BUISCHI; BARBOSA, 1991; CORTELLI et al., 2002; CUTRESS; POWELL; BALL, 1982, GJERMO et al., 1984; RONDEROS; PHILSTROM; HODGES, 2001; TINOCO et al., 1997), além de apresentarem outras limitações metodológicas (BRASIL. MINISTÉRIO DA SAÚDE, 2004). Estes fatores limitam significativamente, a interpretação dos dados disponíveis em estimativas de prevalência, a identificação de possíveis fatores de risco para estas populações e a representatividade e confiabilidade destes estudos (OPPERMANN et al., 2005). O presente estudo realizou um exame clínico periodontal que consistiu no exame de 6 sítios por dentes em todos os dentes presentes, e em toda a população que consentiu com a realização do estudo, o que permitiu uma avaliação mais precisa dos padrões de destruição periodontal.

Além disso, considerando as limitações encontradas nos estudos avaliando doenças periodontais destrutivas, a maioria daqueles realizados em populações isoladas ou que não receberam tratamento periodontal demonstram uma prevalência de $\mathrm{NCl}$ inferior à relatada neste estudo, apesar da grande quantidade de placa e cálculo encontrada nos indivíduos examinados (RONDEROS; PHILSTROM; HODGES, 2001; TIMMERMANN et al., 1998), ou relataram os resultados de seus estudos por meio de médias de NCI (CUTRESS; POWELL; BALL, 1982; LÖE et al., 1986). O único estudo realizado por meio de um protocolo total de exame de $\mathrm{NCl}$ consistindo no exame de 6 sítios por dente, no qual uma prevalência extremamente alta de $\mathrm{NCl}$ foi encontrada ( $90 \%$ dos indivíduos com mais de 35 anos de idade apresentaram no mínimo um dente com $\mathrm{NCl} \geq 6 \mathrm{~mm}$ ), refere-se à uma população indígena e isolada da Guatemala (DOWSETT et al., 2001). Porém, aproximadamente metade do número de indivíduos avaliados neste presente estudo foi examinada (125 indivíduos) por meio de uma amostra de 
conveniência. Além disso, não foi realizado nenhum tipo de avaliação de risco que englobassem fatores demográficos, ambientais e biológicos nesta população.

Todas as comparações entre estudos realizadas neste trabalho devem ser observadas com suas apropriadas limitações, já que é extremamente difícil contabilizar qual é o real impacto da variação da distribuição e freqüência das perdas dentárias encontradas, na prevalência e extensão da perda de inserção periodontal relatada.

O único estudo brasileiro disponível, que avaliou a perda de inserção em 6 sítios por dente em toda a boca, foi conduzido em uma amostra representativa da população adulta urbana da região Sul do Brasil (SUSIN et al., 2004b). Foram encontradas para NCI $\geq 5 \mathrm{~mm}$ e $\geq 7 \mathrm{~mm}$, uma prevalência de $79 \%$ e $52 \%$ com $36 \%$ e $16 \%$ dos dentes afetados, respectivamente. Estas prevalências foram as mais altas encontradas no Brasil, e também semelhantes às encontradas no presente estudo, levando em conta o mesmo grupo etário analisado, que foram $83 \%$ para $\mathrm{NCl} \geq 5 \mathrm{~mm}$ e $52 \%$ para $\mathrm{NCl} \geq 7 \mathrm{~mm}$ com uma extensão de $25 \%$ e $11 \%$, respectivamente.

Baelum, Fejerskov e Manji (1988), em uma população adulta do Quênia, empregou um exame periodontal em 4 sítios em toda a boca, e mostrou que 90 a $99 \%$ dos indivíduos de $35-44,45-54$ e 55 anos ou mais apresentaram $\mathrm{NCl} \geq 4 \mathrm{~mm}$, e que $35 \%, 55 \%$ e $80 \%$ dos indivíduos nestes mesmos grupos etários apresentaram $\mathrm{NCl} \geq 7 \mathrm{~mm}$. Os valores correspondentes em estimativa de prevalência foram bem similares aos do presente estudo, para $\mathrm{NCI} \geq 4 \mathrm{~mm}$ de 91 a $95 \%$, porém discretamente mais altos para $\mathrm{NCl}$ $\geq 7 \mathrm{~mm}: 47 \%, 80 \%$ e $89 \%$.

Os resultados desse estudo indicaram que perda de inserção moderada e severa foi muito mais prevalente nesta população jovem, do que em outras populações estudadas em países em desenvolvimento e outras populações isoladas. Timmermann et 
al. (1998), observou a presença de $\mathrm{NCl} \geq 5 \mathrm{~mm}$ em $8 \%$ dos jovens de 15-25 anos na Indonesia, contrastando com uma prevalência correspondente de 19\% nesta população isolada de 15-25 anos de idade. No Brasil (SUSIN, 2004), foi encontrada uma prevalência de $20 \%$ de $\mathrm{NCl} \geq 5 \mathrm{~mm}$ em um grupo de jovens urbanos de 14-29 anos, prevalência esta pouco mais baixa que a correspondente de $26 \%$ encontrada no presente estudo. No Quênia (BAELUM; FEJERSKOV; MANJI, 1988), menos de 1\% dos indivíduos de 15-24 anos apresentaram ao menos um dente com $\mathrm{NCl} \geq 7 \mathrm{~mm}$, em comparação com a prevalência de 8\% correspondente na presente população de 15-24 anos de idade.

Por outro lado, quando os resultados deste estudo são comparados com levantamentos nacionais realizados em países desenvolvidos, foram encontradas discrepâncias maiores entre as estimativas de prevalência. No levantamento NHANES III (ALBANDAR; BRUNELLE; KINGMAN, 1999), 20\% e 7\% dos adultos de 30-90 anos de idades apresentaram $\mathrm{NCl} \geq 5 \mathrm{~mm}$ e $\geq 7 \mathrm{~mm}$, respectivamente. As prevalências correspondentes para o presente estudo foram aproximadamente 4 e 7,5 vezes maiores para $\mathrm{NCl} \geq 5 \mathrm{~mm}$ e $\geq 7 \mathrm{~mm}$, respectivamente. No entanto, o levantamento utilizou um protocolo parcial de exame clínico, fato que tende a subestimar a prevalência de perda clínica de inserção periodontal (OWENS et al., 2003). Porém, em um levantamento nacional conduzido recentemente na população adulta da França (BOURGEOIS; BOUCHARD; MATTOUT, 2007), onde um protocolo total de exame clínico periodontal consistindo na avaliação de 6 sítios em todos os dentes foi empregado, foi encontrada uma prevalência aproximada de $47 \%$ dos indivíduos de $35-64$ anos com $\mathrm{NCl} \geq 5 \mathrm{~mm}$ e $6 \%$ com $\mathrm{NCl} \geq 8 \mathrm{~mm}$. Este relato somente reforça e encoraja a realização de protocolos totais de exame clínico quando da realização de levantamentos epidemiológicos estudando doenças periodontais destrutivas. No entanto, limitações quanto ao tempo e recursos 
financeiros ainda representam um empecilho para a realização deste tipo de protocolo em estudos epidemiológicos, em nível nacional.

O número de indivíduos que vivem na população estudada (358), levando à um tamanho de amostra limitado (195 indivíduos dentados), não afetou nem os resultados nem a análise de dados realizada no presente estudo (ver teste Hosmer e Lemeshow Goodness-of-fit e área sob a curva ROC, página 55). Porém, grupos etários idosos (50 ou mais anos de idade) não puderam ser distinguidos para a avaliação da prevalência, extensão e severidade de $\mathrm{NCl}$ por esta razão. Pelo mesmo motivo, indivíduos adultos (30 ou mais anos de idade) não puderam ser distinguidos para a avaliação de risco para $\mathrm{NCl}$.

Mesmo assim a idade, neste estudo, foi um forte preditor de $\mathrm{NCl}$ moderado, fator este comumente associado com doenças periodontais em estudos transversais, tanto em termos de perda de inserção quanto perda óssea, entre indivíduos mais idosos quando em comparação com indivíduos mais jovens (SUSIN et al., 2004b; BAELUM, 1998). Indivíduos com mais de 30 anos mostraram, aproximadamente, 11 vezes maior chance de apresentar $\mathrm{NCl} \geq 5 \mathrm{~mm}$. No entanto, esta associação tende a refletir muito mais uma característica cumulativa da perda clínica de inserção periodontal com o tempo, do que uma condição relacionada ao envelhecimento dos tecidos periodontais (ALBANDAR, 2002; HEITZ-MAYFIELD, 2005).

Levantamentos epidemiológicos têm mostrado consistentemente que as doenças periodontais são mais prevalentes e severas em indivíduos do gênero masculino, quando em comparação com o gênero feminino (SUSIN et al., 2004b; ALBANDAR, 2002). Este estudo não verificou nenhuma diferença significativa entre os gêneros com relação à prevalência e extensão de $\mathrm{NCl}$ moderado e severo nesta população isolada, bem como nenhuma associação significante nos modelos multivariáveis finais. Nesta população em 
particular, homens e mulheres possuíam aproximadamente a mesma prevalência e intensidade com relação à hábitos de tabagismo e de higiene bucal (dados não apresentados), fatores que podem ter contribuído para estes resultados.

Grandes quantidades de cálculo supra-gengival e placa foram significantemente associados com $\mathrm{NCl} \geq 5 \mathrm{~mm}$ no modelo multivariável final e, quanto maior a \% de sítios exposta ao cálculo supra-gengival, maior a associação encontrada (OR=2,9 e OR=10,6, respectivamente), mas não com $\mathrm{NCl} \geq 7 \mathrm{~mm}$. Indivíduos portadores de mais que $75 \%$ dos sítios com placa tiveram aproximadamente 3 vezes mais chance de apresentar perda de inserção moderada. Os estudos disponíveis que avaliaram o impacto da má higiene bucal e fatores de retenção de placa, tais como o cálculo supra-gengival, mostraram associação positiva entre grandes quantidades de cálculo supra-gengival e a ocorrência de perda clínica de inserção (ALBANDAR, 2002; SUSIN; ALBANDAR, 2005).

O tabagismo, nesta população isolada, foi o maior e único preditor para $\mathrm{NCl} \geq$ $7 \mathrm{~mm}$. Comparados à não-fumantes, fumantes e ex-fumantes apresentaram 2 a 8 vezes mais chance de apresentar $\mathrm{NCl} \geq 5 \mathrm{~mm}$ e $\geq 7 \mathrm{~mm}$, respectivamente. Esta associação foi observada tanto entre os indivíduos adultos quanto nos indivíduos jovens, onde uma menor contribuição da exposição cumulativa do tabaco é encontrada. Esta forte associação entre o tabagismo e a alta prevalência e severidade de doenças periodontais destrutivas está de acordo com os achados de vários estudos realizados em indivíduos adultos em populações urbanas (HEITZ-MAYFIELD, 2005; SUSIN et al., 2004b; TOMAR; ASMA, 2000), e também em estudos onde indivíduos jovens foram analisados (HASHIM; THOMSON; PACK, 2001; SUSIN; ALBANDAR, 2005).

A variável independente grupo étnico/raça não foi incluída neste estudo já que, na população alvo, uma definição clara entre as etnias/raças não foi passível de 
determinação devido à grande miscigenação presente, o que ocorre também em diversas regiões do Brasil (HARRIS et al., 1993; PIZA; ROSEMBERG, 2002; TURRA; VENTURI, 1998) podendo levar a erros de classificação. Além disso, em similaridade com outras comunidades isoladas (Ex: comunidades indígenas brasileiras), não existe nenhum tipo de segregação da sociedade baseada na origem racial ou étnica, não havendo, portanto, necessidade desta classificação (BHOPAL, 2004).

Do ponto de vista estatístico, o número de 2 indivíduos diabéticos dentados encontrado neste estudo, foi muito pequeno para que se pudesse declarar com poder suficiente, se a presença de Diabetes mellitus influenciou ou não às condições periodontais encontradas nesta população. 


\section{CONCLUSÃO}

Com base nos resultados encontrados por este estudo, podemos concluir que:

1) Esta população apresentou prevalência e severidade de perda clínica de inserção altas, porém, com baixa extensão;

2) A alta prevalência de perda clínica de inserção severa encontrada nos indivíduos jovens, e o fato de que indicadores de risco tradicionais também foram encontrados nesta população, podem indicar fatores microbiológicos ou a susceptibilidade do hospedeiro ao efeito destas exposições ambientais como fatores-chave para a alta prevalência de $\mathrm{NCl}$ encontrada nesta população 


\section{REFERÊNCIAS ${ }^{1}$}

Abel L, Dessein AJ. Genetic epidemiology of infectious diseases in humans: design of population-based studies. Emerg Infect Dis 1998;4:593-603.

Ainamo J, Barnes DE, Beagrie G, Cutress T, Martin J, Sardo-Infirri J. Development of the World Health Organization (WHO) Community Periodontal Index of Treatment Needs (CPITN). Int Dent J 1982;32:281-91.

Ainamo J, Bay I. Problems and proposals for recording gingivitis and plaque. Int Dent $\mathrm{J}$ 1975;25:229-35.

American Academy of Periodontology (AAP). Position paper: epidemiology of periodontal diseases. J Periodontol 2005;76:1406-19.

Albandar JM. Global risk factors and risk indicators for periodontal diseases. Periodontol 2000 2002;29:177-206.

Albandar JM, Rams TE. Global epidemiology of periodontal diseases: An overview. Periodontol 2000 2002;29:7-10.

Albandar JM, Brunelle JA, Kingman A. Destructive periodontal disease in adults 30 years of age and older in the United States, 1988-1994. J Periodontol 1999;70:13-29.

Albandar JM, Buischi YA, Barbosa MF. Destructive forms of periodontal disease in adolescents. A 3-year longitudinal study. J Periodontol 1991;62:370-6.

Albandar JM, Brown LJ, Brunelle JA, Löe H. Gingival state and dental calculus in earlyonset periodontitis. J Periodontol 1996;67:953-9.

\footnotetext{
${ }^{1}$ De acordo com Estilo Vancouver. Abreviatura de periódicos segundo base de dados MEDLINE
} 
Albandar JM, Kingman A, Brown LJ, Löe H. Gingival inflammation and subgingival calculus as determinants of disease progression in early-onset periodontitis. J Clin Periodontol 1998;25:231-7.

Arantes R. Saúde bucal dos povos indígenas no Brasil: panorama atual e perspectivas. In: Coimbra Jr CEA, Santos RV, Escobar AL. Epidemiologia e saúde dos povos indígenas no Brasil. Rio de Janeiro: Fiocruz / ABRASCO; 2003. p. 49-72.

Arantes R, Santos RV, Coimbra Jr CEA. Saúde bucal na população indígena Xavánte de Pimentel Barbosa, Mato Grosso, Brasil. Cad Saúde Pública 2001;17:375-84.

Axelsson P, Albandar JM, Rams TE. Prevention and control of periodontal diseases in developing and industrialized nations. Periodontol 2000 2002;29:235-46.

Baelum V. The epidemiology of destructive periodontal disease: causes, paradigms, problems, methods and empirical evidence [Doctorate Thesis]. Aarhus: Royal Dental College, Faculty of Dentistry, University of Aarhus; 1998.

Baelum V, Lopez R. Defining and classifying Periodontitis: need for a paradigm shift? Eur J Oral Sci 2003;111 2-6.

Baelum V, Lopez R. Periodontal epidemiology: towards social science or molecular biology? Community Dent Oral Epidemiol 2004;32:239-49.

Baelum V, Papapanou PN. CPITN and the epidemiology of periodontal disease. Community Dent Oral Epidemiol 1996;24:367-8.

Baelum V, Fejerskov O, Manji F. Periodontal disease in adult Kenyans. J Clin Periodontol 1988;15:445-52.

Baelum V, Chen X, Manji F, Luan W-M, Fejerskov O. Profiles of destructive periodontal disease in different populations. J Periodont Res 1996;31:17-26.

Beck JD. Methods of assesing risk for periodontitis and developing multifactorial models. J Periodontol 1994; 65:468-78. 
Beck JD, Löe H. Epidemiological principles in studying periodontal diseases. Periodontol 2000 1993;2:34-45.

Beck JD, Pankow J, Tyroler HA, Offenbacher S. Dental infections and atherosclerosis. Am Heart J 1999;138:S528-33.

Bhopal R. Glossary of terms relating to ethnicity and race: for reflection and debate. J Epidemiol Community Health 2004;58:441-5.

Borges-Yanez SA, Maupome G, Jimenez-Garcia G. Validity and reliability of partial examination to assess severe periodontitis. J Clin Periodontol 2004;31(2):112-8.

Borrell LN, Papapanou PN. Analytical epidemiology of periodontitis. J Clin Periodontol 2005; 32(Suppl. 6):132-58.

Bourgeois D, Bouchard $\mathrm{P}$, Mattout $\mathrm{C}$. Epidemiology of periodontal status in dentate adults in France, 2002-2003. J Periodontal Res 2007;42:219-27.

Bowling A. Mode of questionnaire administration can have serious effects on data quality. J Public Health 2005;27:281-91.

Bowling A, Bond M, Jenkinson C, Lamping D. Short form-36 (SF-36) health survey questionnaire: which normative data should be used? Comparisons between the norms provided by the Omnibus survey in Britain. The health survey for England and the Oxford health and lifestyle survey. J Public Health Med 1999;21:255-70.

Brasil. Mininstério da Saúde. SB 2000. Condições de saúde bucal da população brasileira 2002-2003. Resultados principais. Brasília,DF: Ministério da Saúde, Secretaria da Atenção à Saúde, Departamento de Atenção Básica, Coordenação Nacional de Saúde Bucal; 2004.

Brown LJ, Brunelle JA, Kingman A. Periodontal status in the United States, 1988-1991: prevalence, extent, and demographic variation. J Dent Res 1996;75(Spec n.):672-83.

Chaves MM. Odontologia social. São Paulo: Artes Médicas; 1986. 
Coimbra Jr CEA, Santos RV. Saúde, minorias e desigualdades: algumas teias de interrelações, com ênfase nos povos indígenas no Brasil. Ciênc saúde coletiva 2000;5:125-32.

Cortelli JR, Cortelli SC, Pallos D, Jorge AO. Prevalence of aggressive periodontitis in adolescents and young adults from Vale do Paraíba. Pesqui Odontol Bras 2002;16:163-8.

Cutress TW, Powell RN, Ball ME. Differing profiles of periodontal disease in two similar South Pacific island populations. Community Dent Oral Epidemiol 1982;10:193-203.

Diamanti-Kipioti A, Papapanou PN, Moraitaki-Tsami A, Lindhe J, Mitsis F. Comparative estimation of periodontal conditions by means of different index systems. J Clin Periodontol 1993;20(9):656-61.

Donnelly CJ, Thomson LA, Stiles HM, Brewer C, Neel JV, Brunelle JÁ. Plaque, caries, periodontal diseases, and acculturation among Yanomamö Indians, Venezuela. Community Dent Oral Epidemiol 1977;5:30-39.

Dowsett AS, Archila L, Segreto VA, Eckert GJ, Kowolik MJ. Periodontal disease status of an indigenous population of Guatemala, Central America. J Clin Periodontol 2001;28:66371.

Dye BA, Selwitz RH. The relationship of selected measures of periodontal status and demographic and behavioral risk factors. J Clin Periodontol 2005;32:798-808.

Emrich LJ, Sholssman M, Genco RJ. Periodontal disease in non-insulin-dependent diabetes mellitus. J Periodontol 1991;62:123-30.

Estados Unidos. DHHS. Dental diseases. In: Samet JM, Norman LA, Wilbanks C, editores. The health consequences of smoking: a report of the surgeon general. Washington DC: Dep of Health and Human Services;2004. p. 732-66.

Fratucci MVB. Alguns aspectos das condições de saúde bucal de uma população indígena Guarani Mbyá no Município de São Paulo [Dissertação de Mestrado]. São Paulo: Faculdade de Saúde Pública da Universidade de São Paulo; 2000.

Frias AC, Antunes JLF, Narvai PC. Precisão e validade de levantamentos epidemiológicos de saúde bucal: cárie dentária na cidade de São Paulo, 2002. Rev Bras Epidemiol 2004;7:2. 
Galati C. Aspectos da saúde bucal de caiçaras e indígenas da região da estação ecológica Juréia-Itatins, Iguape, São Paulo, 2003 [Dissertação de Mestrado]. São Paulo: Faculdade de Saúde Pública da Universidade de São Paulo; 2003.

Genco RJ, Jeffcoat M, Caton Jr J, Papapanou PN, Grossi S, Johnson N et al. Consensus report periodontal diseases: epidemiology and diagnosis. Ann Periodontol 1996;1:216-22.

Gjermo P, Bellini HT, Pereira Santos V, Martins JG, Ferracyoli JR. Prevalence of bone loss in a group of Brazilian teenagers assessed on a bite-wing radiographs. J Clin Periodontol 1984;11:104-13.

Gjermo P, Rösing CK, Susin C, Oppermann RV. Periodontal diseases in Central and South America. Periodontol 2000 2002;29:70-8.

Goodson JM. Diagnosis of periodontitis by physical measurement: interpretation from episodic disease hypothesis. J Periodontol 1992; 63(Suppl):373-82.

Greene JC. Discussion: natural history of periodontal disease in man. J Clin Periodontol 1986;13:441.

Grossi SG, Zambom JJ, Ho AW, Koch G, Dunford RG, Machtei EE et al. Assessment of risk for periodontal disease. I. Risk indicators for attachment loss. J Periodontol 1994;65:260-7.

Harris M, Consorte JG, Land J, Byrne B. Who are the whites? Imposed census categories and the racial demography in Brazil. Soc Forces 1993;72:451-62.

Hashim R, Thomson WM, Pack ARC. Smoking in adolescence as predictor of early loss of periodontal attachment. Community Dent Oral Epidemiol 2001;29:130-5.

Heitz-Mayfield LJ. Disease progression: identification of high-risk groups and individuals for periodontitis. J Clin Periodontol 2005;32(Suppl 6):196-209.

Heller W-D, Scherer G, Sennewald E, Adlkofer F. Misclassification of smoking in a followup population in southern Germany. J Clin Epidemiol 1998;51:211-8. 
Hodge P, Michalowicz B. Genetic predisposition to periodontitis in children and young adults. Periodontol 2000 2001;26:113-34.

Hosmer DW, Lemeshow S. Applied logistic regression. New York: John Wiley \& Sons; 2000 .

Hubert L. Kappa revisited. Psycholl Bull 1977; 84: 289-97.

Hujoel PP, del Aquila MA, DeRouen TA, Berqstrom J. A hidden periodontitis epidemic during the 20th century? Community Dent Oral Epidemiol 2003;31:1-6.

Hunt RJ, Fann SJ. Effect of examining half the teeth in a partial periodontal recording of older adults. J Dent Res 1991;70(10):1380-5.

Kingman A, Albandar JM. Methodological aspects of epidemiological studies of periodontal diseases. Periodontol 2000 2002;29:11-30.

Kingman A, Morrison E, Löe H, Smith J. Systematic errors in estimating prevalence and severity of periodontal disease. J Periodontol 1988;59(11):707-13.

Last JM, editor. A dictionary of epidemiology. $4^{\text {th }}$ ed. New York: Oxford University Press; 2001.

Levy PS, Lemeshow S. Sampling of populations. Methods and applications. 3rd ed. New York: John Wiley; 1999.

Löe $H$, Anerud A, Boysen H, Morrison E. Natural history of periodontal disease in man. Rapid, moderate and no loss of attachment in Sri Lankan laborers 14 to 46 years of age. J Clin Periodontol 1986;13:431-45.

Löe $\mathrm{H}$, Anerud A, Boysen $\mathrm{H}$, Smith $\mathrm{M}$. The natural history of periodontal disease in man. The rate of periodontal destruction before 40 years of age. J Periodontol 1978;49:607-20. 
Marques RAA. Condição de saúde periodontal no Município de São Paulo em 1986 e 1998 [Dissertação de Mestrado]. São Paulo: Faculdade de Saúde Pública da Universidade de São Paulo; 2000.

McCaul LK, Jenkins WM, Kay EJ. The reasons for extraction of various tooth types in Scotland: a 15-year follow up. J Dent 2001;29:401-7.

Neely AL, Holford TR, Löe $H$, Anerud A, Boysen $H$. The natural history of periodontal disease in man. Risk factors for progression of attachment loss in individuals receiving no oral health care. J Periodontol 2001;72:1006-15.

Niswander JD. Further Studies on the Xavánte Indians VII. The Oral Status of the Xavántes of Simões Lopes. Am J Hum Genet 1967;19:543-53.

Oliver RC, Brown LJ, Löe H. Periodontal diseases in the United States population. J Periodontol 1998;69:269-78.

Oppermann RV, Susin C, Cortelli SC, Rösing CK, Araújo MWB, Costa FO, et al. Epidemiologia das doenças periodontais. Rev Periodontia 2005;15(4):62-76.

Owens JD, Dowsett SA, Eclert GJ, Zero DT, Kowolik MJ. Partial-mouth assessment of periodontal disease in an adult population of the United States. J Periodontol 2003;74:1206-13.

Papapanou PN. Periondontal diseases: epidemiology. Ann Periodontol 1996;1:14-36.

Patrick DL, Cheadle A, Thompson DC, Diehr P, Koepsell T, Kinne S. The validity of selfreported smoking: a review and meta-analysis. Am J Public Health 1994;84:1086-93.

Persson GR. Site-based versus subject-based periodontal diagnosis. Periodontol 2000 2005;39:145-63.

Petersen PE, Bourgeois D, Ogawa H, Estupinan-Day S, Ndiaye C. The global burden of oral diseases and risks to oral health. Bull World Health Org 2005;83:661-9. 
Piza E, Rosemberg F. Cor nos censos brasileiros. In: Carone I, Bento MAS (organizadores). Psicologia social do racismo: estudos sobre branquitude e branqueamento no Brasil. Petrópolis: Vozes; 2002. p. 91-120.

Ronderos M, Pilhstrom BL, Hodges JS. Periodontal disease among indigenous people in the Amazon rain forest. J Clin Periodontol 2001;28:995-1003.

Rösing CK, Oppermann RV. Epidemiologia das doenças periodontais. In: Opperman RV, Rösing CK. Periodontia: ciência e clínica. São Paulo: Artes Médicas, 2001.

Rouquaryol MZ, Almeida Filho N. Epidemiologia \& saúde. 4ªEd. Rio de Janeiro: Medsi; 1994.

Russell AL. Epidemiology of periodontal disease. Int Dent J 1967;17:282-96.

Schatzle M, Löe H, Burgin W, Anerud A, Boysen H, Lang NP. Clinical course of chronic periodontitis. I. Role of gingivitis. J Clin Periodontol 2003a;30:887-901.

Schatzle M, Löe H, Lang NP, Heitz-Mayfield LJ, Burgin W, Anerud A, et al. Clinical course of chronic periodontitis. III. Patterns, variations and risks of attachment loss. J Clin Periodontol 2003b;30:909-18.

Schuman H, Presser S. Questions and answers in attitude surveys. New York: Academic Press; 1981.

Scott DA, Palmer RM, Stapleton JA. Validation of smoking status in clinical research into inflammatory periodontal disease. J Clin Periodontol 2001;28:715-22.

Segundo TK, Ferreira EF, Costa JE. Doença periodontal na comunidade negra dos Arturo's, Contagem, Minas Gerais, Brasil. Cad Saúde Pública 2004;20:596-603.

Shrout P, Fleiss J. Intraclass correlations: uses in assessing rater reliability. Psycol Bull 1979;86:420-28.

Spiekerman CF, Hujoel PP, DeRouen TA. Bias induced by self-reported smoking on Periodontitis - systemic disease associations. J Dent Res 2003;82:345-9. 
Solskolne WA. Epidemiological and clinical aspects of periodontal diseases in diabetics. Ann Periodontol 1998;3:3-12.

Stirnadel HA, Beck $H$, Alpers MP, Smith TA. Heritability and segregartion analysis of immune responses to specific malaria antigens in Papua, New Guinea. Genet Epidemiol 1999;17(1):16-34.

Susin C. Periodontal diseases in a representative urban population in south Brazil [Doctor Odontologiae Thesis]. Bergen: University of Bergen; 2004

Susin C, Albandar JM. Aggressive periodontitis in an urban population in southern Brasil. J Periodontol 2005;76:468-75.

Susin C, Kingman A, Albandar JM. Effect of partial recording protocols on estimates of prevalence of periodontal disease. J Periodontol 2005;76(2):262-7.

Susin C, Oppermann RV, Haugejorden O, Albandar JM. Periodontal attachment loss attributable to smoking in an urban brazilian population. J Clin Periodontol 2004;31:951-8.

Susin C, Vecchia CFD, Oppermann RV, Haugejorden O, Albandar JM. Periodontal attachment loss in a urban population of brazilian adults: effect of demographic, behavioral, and environmental risk indicators. J Periodontol 2004;75:1033-41.

The Expert Committee on the Diagnosis and Classification of Diabetes Mellitus. Report of the Expert Committee on the Diagnosis and Classification of Diabetes Mellitus. Diabetes Care 2003;26:S4-S20.

Timmerman MF, Van der Weijden GA, Armand S, Abbas F, Winkel EG, Van Winkelhoff $A J$, et al. Untreated periodontal disease in Indonesian adolescents. Clinical and microbiological baseline data. J Clin Periodontol 1998;25:215-24.

Tinoco EM, Beldi MI, Loureiro CA, Lana M, Campedelli F, Tinoco NM, et al. Localized juvenile periodontitis and Actinobacillus actinomycetencomitans in a Brazilian population. Eur J Oral Sci 1997;105:9-14.

Tomar SL, Asma S. Smoking-atributable periodontitis in the United States: findings from NHANES III. J Periodontol 2000;71:743-51. 
Tumang AJ, Piedade EF. Cárie dental, doenças periodontais e higiene dental em indígenas brasileiros. Bol Oficina Sanit Panam 1968;64:103-09.

Turra C, Venturi G. Racismo cordial: a mais completa análise sobre o preconceito de cor no Brasil. São Paulo: Ática; 1998.

Van Der Velden U. Letter to the editor. Diagnosis of periodontitis. J Clin Periodontol 2000;27:960-1.

Van Der Velden U. Purpose and problems of periodontal disease classification. Periodontol 2000 2005;39:13-21.

Van Der Velden U, Abbas F, Armand S, Loos BG, Timmerman MF, Van der Weijden GA, et al. Java project on periodontal diseases. The natural development of periodontitis: risk factors, risk predictors and risk determinants. J Clin Periodontol 2006;33:540-8.

Wagenknecht LE, Burke GL, Perkins LL, Haley NJ, Friedman GD. Misclassification of smoking status in the CARDIA study: a comparison of self-report with serum cotinine levels. Am J Public Health 1992;82:33-6.

Wells AJ, English PB, Posner SF, Wagenknecht LE, Perez-Stable EJ. Misclassification rates for current smokers misclassified as nonsmokers. Am J Public Health 1998;88:15039.

Woodward M, Tunstall-Pedoe $\mathrm{H}$. An iterative technique for identifying smoking deceivers with application to the Scottish Heart Health Study. Prev Med 1992;21:88-97.

World Health Organization (WHO). Oral health surveys: basic methods. $4^{\mathrm{a}}$ ed. Geneva: OMS; 1997. 
ANEXO A - Parecer do Comitê de Ética em Pesquisa

\author{
UNIVERSIDADE DE SÃO PAULO \\ FACULDADE DE ODONTOLOGIA
}

\title{
PARECER DE APROVAÇÃO \\ Protocolo 49/04
}

Com base em parecer de relator, o Comitê de Ética em Pesquisa, APROVOU o protocolo de pesquisa "Análise da prevaléncia das doenças periodontal e cárie em populações ísoladas do litoral do Rio de Janeiro", de responsabilidade da pesquisadora Prisclla Corraini, sob orientação do Professor Doutor Francisco Emilio Pustiglioni.

Tendo em vista a legislação vigente, devem ser encaminhados a este Comitê relatórios anuais referentes ao andamento da pesquisa e ao término cópia do trabalho em "cd". Qualquer emenda do projeto original deve ser apresentada a este CEP para apreciação, de forma clara e sucinta, identificando a parte do protocolo a ser modificada e suas justificativas.

Săo Paulo, 29 de abril de 2004

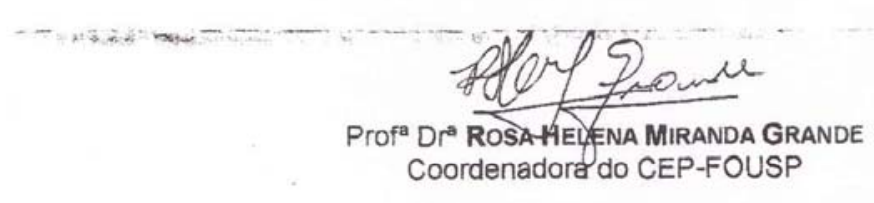

Av. Prof. Lineu Prestes, 2227 - Cidade Universitária "Armando de Salles Oliveira" CEP 05508-900 Săo Paulo - SP - Diretoria Telefax: (011) 3091-0062/3091-7817/3091-7860 - Compras (011) 3091-7895 
ANEXO B - Termo de Consentimento Livre e Esclarecido

\title{
UNIVERSIDADE DE SÃO PAULO \\ Faculdade de Odontologia \\ Departamento de Estomatologia \\ Disciplina de Periodontia
}

\section{TERMO DE CONSENTIMENTO LIVRE E ESCLARECIDO}

\author{
Projeto de iniciação científica: \\ “AVALIAÇÃO DA PREVALÊNCIA DE DOENÇA PERIODONTAL E CÁRIE EM \\ POPULAÇÕES ISOLADAS DO LITORAL DO RIO DE JANEIRO”
}

Você é convidado a participar de uma pesquisa que levantará dados referentes ao seu estado de saúde bucal através do Projeto Sorriso Marinho, com enfoque ao comportamento da cárie dental e de sua saúde gengival. Este estudo é feito pela aluna de mestrado da Faculdade de Odontologia da USP PRISCILA CORRAINI, sendo orientada pelo Prof. Dr. FRANCISCO EMILIO PUSTIGLIONI.

Se você concordar em participar da pesquisa, os procedimentos realizados serão a coleta de dados (em forma de uma tabela) que serão obtidos através de um exame de suas gengivas com um instrumento de medida, da realização de um índice de placa bacteriana e de cárie dental, e além da possível realização de fotografias de sua boca (sem mostrar a face).

Este trabalho não oferece riscos à sua saúde, bem como qualquer tipo de dor ou desconforto, sem causar nenhum tipo de interferência tanto no tempo quanto na qualidade do atendimento no Projeto Sorriso Marinho.

Tanto seu nome quanto seus registros e seus arquivos fotográficos serão confidenciais, sendo apenas as informações obtidas pelo exame gengival utilizadas como dados para a pesquisa. Sua decisão de participar ou não da pesquisa não afetará seu atendimento pelo Projeto Sorriso Marinho, podendo também desistir a qualquer momento.

Você terá uma via deste documento.

Eu li todas as informações. Todas as dúvidas foram esclarecidas. Eu forneço meu consentimento para participar da pesquisa proposta.

NOME:

ASSINATURA DO SUJEITO DE PESQUISA OU RESPONSÁVEL

LEGAL:

DATA:

ASSINATURA DO PESQUISADOR:

Telefone para contato: (11) 30225523

DATA: 
ANEXO C - Ficha clínica

Nome:

Arco superior / face vestibular

\begin{tabular}{|c|c|c|c|c|c|c|c|c|c|c|c|c|c|c|}
\hline & 17 & 16 & 15 & 14 & 13 & 12 & 11 & 21 & 22 & 23 & 24 & 25 & 26 & 27 \\
\hline \multicolumn{15}{|l|}{ LEC-MG } \\
\hline PCS & & & & & & & & & & & & & & \\
\hline $\mathrm{NCl}$ & & & & & & & & & & & & & & \\
\hline placa/ cálculo? & & & & & & & & & & & & & & \\
\hline
\end{tabular}

Arco superior / face palatina

\begin{tabular}{|c|c|c|c|c|c|c|c|c|c|c|c|c|c|c|}
\hline & 17 & 16 & 15 & 14 & 13 & 12 & 11 & 21 & 22 & 23 & 24 & 25 & 26 & 27 \\
\hline \multicolumn{15}{|l|}{ LEC-MG } \\
\hline PCS & & & & & & & & & & & & & & \\
\hline $\mathrm{NCl}$ & & & & & & & & & & & & & & \\
\hline cal cálculo? & & & & & & & & & & & & & & \\
\hline
\end{tabular}

Arco inferior / face vestibular

\begin{tabular}{|c|c|c|c|c|c|c|c|c|c|c|c|c|c|c|}
\hline \multirow{2}{*}{\multicolumn{15}{|c|}{ LEC-MG }} \\
\hline & & & & & & & & & & & & & & \\
\hline PCS & & & & & & & & & & & & & & \\
\hline $\mathrm{NCl}$ & & & & & & & & & & & & & & \\
\hline culo? & & & & & & & & & & & & & & \\
\hline
\end{tabular}

Arco inferior / face lingual

LEC-MG

PCS

$\mathrm{NCl}$

placa/ cálculo?

\begin{tabular}{|l|l|l|l|l|l|l|l|l|l|l|l|l|l|}
\hline 47 & 46 & 45 & 44 & 43 & 42 & 41 & 31 & 32 & 33 & 34 & 35 & 36 & 37 \\
\hline & & & & & & & & & & & & & \\
\hline & & & & & & & & & & & & & \\
\hline & & & & & & & & & & & & & \\
\hline & & & & & & & & & & & & & \\
\hline
\end{tabular}

İndice CPO-D = 